\title{
Article \\ Online, Group-Based Psychological Support for Adolescent and Young Adult Cancer Survivors: Results from the Recapture Life Randomized Trial
}

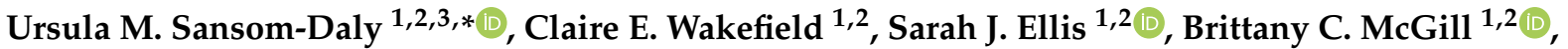 \\ Mark W. Donoghoe 1,2,4 (-) Phyllis Butow ${ }^{5}$, Richard A. Bryant ${ }^{6}$, Susan M. Sawyer $7,8,9$, Pandora Patterson 10,11, \\ Antoinette Anazodo 1,3,12, Megan Plaster ${ }^{13}$, Kate Thompson ${ }^{14,15}$, Lucy Holland 16,17, Michael Osborn ${ }^{18}{ }^{(D)}$, \\ Fiona Maguire ${ }^{3}$, Catherine O'Dwyer ${ }^{3}{ }^{\circledR 0}$, Richard De Abreu Lourenco ${ }^{19}$, Richard J. Cohn ${ }^{1,2}$ \\ and The Recapture Life Working Party ${ }^{\dagger}$
}

check for updates

Citation: Sansom-Daly, U.M.; Wakefield, C.E.; Ellis, S.J.; McGill, B.C.; Donoghoe, M.W.; Butow, P.; Bryant, R.A.; Sawyer, S.M.; Patterson, P.; Anazodo, A.; et al. Online, Group-Based Psychological Support for Adolescent and Young Adult Cancer Survivors: Results from the Recapture Life Randomized Trial. Cancers 2021, 13, 2460. https:// doi.org/10.3390/cancers13102460

Academic Editors: Saskia F.A. Duijts and Evelien R. Spelten

Received: 31 March 2021

Accepted: 3 May 2021

Published: 18 May 2021

Publisher's Note: MDPI stays neutral with regard to jurisdictional claims in published maps and institutional affiliations.

Copyright: (c) 2021 by the authors. Licensee MDPI, Basel, Switzerland. This article is an open access article distributed under the terms and conditions of the Creative Commons Attribution (CC BY) license (https:/ / creativecommons.org/licenses/by/ $4.0 /)$.
1 School of Women's and Children's Health, UNSW Sydney, Kensington, NSW 2033, Australia; c.wakefield@unsw.edu.au (C.E.W.); sarah.ellis@unsw.edu.au (S.J.E.); b.mcgill@unsw.edu.au (B.C.M.); m.donoghoe@unsw.edu.au (M.W.D.); antoinette.anazodo@unsw.edu.au (A.A.); r.cohn@unsw.edu.au (R.J.C.)

2 Behavioural Sciences Unit, Kids Cancer Centre, Sydney Children's Hospital, Randwick, NSW 2031, Australia

3 Sydney Youth Cancer Service, Nelune Comprehensive Cancer Centre, Prince of Wales Hospital, Randwick, NSW 2031, Australia; Fiona.Maguire@health.nsw.gov.au (F.M.);

Cath.ODwyer@health.nsw.gov.au (C.O.)

4 Stats Central, Mark Wainwright Analytical Centre, UNSW Sydney, Kensington, NSW 2033, Australia

5 Centre for Medical Psychology \& Evidence-Based Decision-Making (CeMPED), School of Psychology, University of Sydney, Sydney, NSW 2050, Australia; phyllis.butow@sydney.edu.au

6 School of Psychology, UNSW Sydney, Kensington, NSW 2033, Australia; r.bryant@unsw.edu.au

7 Department of Paediatrics, The University of Melbourne, Melbourne, VIC 3052, Australia; susan.sawyer@rch.org.au

8 Royal Children's Hospital Centre for Adolescent Health, Melbourne, VIC 3052, Australia

9 Murdoch Children's Research Institute, Melbourne, VIC 3052, Australia

10 Research, Evaluation and Policy Unit, CanTeen, Sydney, NSW 2042, Australia; pandora.patterson@canteen.org.au

11 Faculty of Medicine and Health, The University of Sydney, Sydney, NSW 2050, Australia

12 Kids Cancer Centre, Sydney Children's Hospital, Randwick, NSW 2031, Australia

13 Western Australia Youth Cancer Service, Sir Charles Gairdner Hospital, WA 6009, Australia; Megan.Plaster@health.wa.gov.au

14 Victorian Adolescent \& Young Adult Cancer Service, Peter MacCallum Cancer Centre, Melbourne, VIC 3000, Australia; kate.thompson@petermac.org

15 Department of Social Work, The University of Melbourne, Melbourne, VIC 3010, Australia

16 Queensland Child and Youth Clinical Network, Clinical Excellence Queensland, Herston, QLD 4006, Australia; Lucy.Holland@qut.edu.au

17 School of Nursing, Queensland University of Technology, Brisbane, QLD 4000, Australia

18 Youth Cancer Service SA/NT, Royal Adelaide Hospital, Adelaide, SA 5000, Australia; michael.osborn@sa.gov.au

19 Centre for Health Economics Research and Evaluation, University of Technology Sydney, Haymarket, NSW 2000, Australia; richard.deabreulourenco@chere.uts.edu.au

* Correspondence: ursula@unsw.edu.au; Tel.: +61-2-9382-3114

+ Membership of The Recapture Working Party is provided in Acknowledgments.

Simple Summary: Adolescents and young adult cancer survivors are vulnerable to psychological distress after completing cancer treatment. Telehealth (online videoconferencing) interventions may be able to address the gap in tailored, evidence-based supportive interventions. We evaluated an online, group-based, videoconference-delivered cognitive-behavioral therapy intervention ('Recapture Life') in a randomized trial. Forty cancer survivors between the ages of 15-25 years participated. No positive impacts on participants' quality of life emerged immediately following the intervention, but Recapture Life participants reported using more adaptive coping skills. Recapture Life participants also reported higher negative impact of cancer, anxiety and depression at a 12-month follow-up. Additional analyses suggested that survivors benefitted differently from the two online interventions (Recapture Life vs. peer-support group) depending on how recently they had completed their cancer 
treatment. Our data highlight that different survivor sub-groups may find group-based, telehealth psychological interventions more or less helpful at different points in survivorship.

Abstract: Telehealth interventions offer a practical platform to support adolescent and young adult (AYA) cancer survivors' mental health needs after treatment, yet efficacy data are lacking. We evaluated an online, group-based, videoconferencing-delivered cognitive-behavioral therapy (CBT) intervention ('Recapture Life') in a 3-arm randomized-controlled trial comparing Recapture Life with an online peer-support group, and a waitlist control, with the aim of testing its impact on quality of life, emotional distress and healthcare service use. Forty AYAs $\left(\mathrm{M}_{\mathrm{age}}=20.6\right.$ years $)$ within 24-months of completing treatment participated, together with 18 support persons. No groupwise impacts were measured immediately after the six-week intervention. However, Recapture Life participants reported using more CBT skills at the six-week follow-up $(\mathrm{OR}=5.58,95 \% \mathrm{CI}=2.00-15.56, p=0.001)$ than peer-support controls. Recapture Life participants reported higher perceived negative impact of cancer, anxiety and depression at 12-month follow-up, compared to peer-support controls. Post-hoc analyses suggested that AYAs who were further from completing cancer treatment responded better to Recapture Life than those who had completed treatment more recently. While online telehealth interventions hold promise, recruitment to this trial was challenging. As the psychological challenges of cancer survivorship are likely to evolve with time, different support models may prove more or less helpful for different sub-groups of AYA survivors at different times.

Keywords: adolescent; young adult; survivor; cancer survivorship; psychological interventions; online videoconferencing; telehealth; cognitive-behavioral therapy; quality of life; cancer continuum

\section{Introduction}

Adolescent and young adult (AYA) cancer survivors experience high rates of common mental health difficulties, such as depression and anxiety disorders [1,2]. For these survivors, the documented stresses associated with their cancer diagnosis collide with an already-challenging developmental period [1,3]. The risk of onset of mental health concerns peaks during the AYA years, with $75 \%$ of mental disorders commencing by the age of 24 years [4,5]. Developing and evaluating interventions to best meet AYA cancer survivors' mental health needs is recognized as an international clinical and research priority [6-8]. This sits within a broader policy context promoting preventative approaches to youth mental health $[9,10]$.

Considerable advances have been made in the development and implementation of age-appropriate, AYA-specific clinical and hospital-based services over the past decade [6,11-15]. However, these services typically focus on AYAs in active phases of cancer treatment. Meeting AYAs' post-cancer care mental health needs can be more difficult as young people leave hospital-based environments to return to their home communities, which may be geographically distant from their treating center [16]. Delivering mental health interventions in AYAs' local communities may best support AYAs' re-integration back into life after cancer [17]. In addition to the practical benefits from reduced travel and its interruption to daily routines, community-based delivery of post-treatment support may also reduce AYAs' identity as a sick 'patient' and facilitate the transition towards a post-cancer identity as a capable, well-functioning adult $[1,18]$.

Online telehealth interventions offering community-based mental health care using videoconferencing technology have proliferated in recent years, and appear ideally placed to meet the unique needs of AYA cancer survivors [19-21]. Concerns around the recent global coronavirus (COVID-19) pandemic have further reinforced the infectious control benefits of remotely-delivered, telehealth interventions, including for young people living with and beyond cancer [22,23]. Telehealth interventions can enhance equity in accessing support by obviating the need for travel (which can be difficult for those with physical symptoms such as pain, fatigue and immobility), overcome the stigma around help-seeking 
for mental health (which is particularly pertinent for AYAs) by providing a private and individually-tailored mode of delivery [22,24-27], and broaden the geographic reach of specialist psycho-oncology services that are often clustered in major cities. Recent data indicate that $>85 \%$ of households in Australia [28], the US [29], and UK [30] have access to the internet, which suggests that dissemination of telehealth models would also be feasible at scale [21].

Clinical and research communities have welcomed online interventions, including in oncology [31,32]. Early evidence supports their acceptability and utility, both to cancer survivors and professionals [26,33-35]. Safety and feasibility data are however, only just emerging in AYA cancer survivors [35,36], while efficacy data are lacking. There is strong evidence that cognitive-behavioral therapy (CBT) is effective in addressing mental health disorders, such as anxiety and depression among AYAs outside of oncology, including among young people with sub-clinical distress [37-39]. However, this therapeutic approach has yet to be fully evaluated in the AYA oncology context [19,40]. Finally, while it is thought that online mental health interventions may reduce the costs incurred both by their users and those delivering them, little cost data are currently available [41,42]. Whether and how online interventions may impact AYAs' subsequent need or desire to use other health- and mental healthcare services is also unknown.

Furthermore, it is likely that some individuals may respond better to online telehealth interventions than others [22], but the question of 'who' responds best remains unknown. The optimal type and timing of online interventions for AYA cancer survivors are also unclear: reviews report mixed results across different types of online support (including websites, videoconferencing-based telehealth interventions, and mobile-phone apps) with efficacy data often lacking $[19,31,40]$. AYAs can also experience heightened distress at several points from cancer diagnosis through to long-term survivorship [1].

We aimed to fill these evidence gaps through a rigorous evaluation of the Recapture Life intervention [43]. Recapture Life is a group-based, videoconferencing-delivered psychological intervention for AYA cancer survivors, facilitated by a psychologist. Informed by adolescent resilience models [44], it uses evidence-based CBT coping strategies, tailored to the key concerns of AYAs [36,43]. Recapture Life is delivered at treatment completion, recognized as a challenging period in the cancer trajectory, and a time when distress can peak and mental health concerns emerge $[1,16]$. This approach (deliberately targeting groups known to be vulnerable to developing mental health disorders by virtue of particular risk factors, in this case, a cancer diagnosis) is often referred to as 'selective-preventative' $[45,46]$.

We have previously reported that Recapture Life is feasible and safe to deliver, as well as acceptable to AYAs and psychologists $[33,36]$. Here, we examine the efficacy and cost of Recapture Life in the early cancer survivorship period, compared to both an active peersupport group control and a waitlist control, within a three-arm randomized-controlled trial (RCT). Peer-support groups are commonly used in oncology, and may be particularly beneficial for AYAs from a developmental perspective. However, they have not yet been rigorously evaluated $[19,47]$. The use of the peer-support control group was designed to disentangle any specific benefits of group-based CBT, from the more general, non-specific supportive benefits of group-based peer-support. This gold-standard trial design also controlled for participants' expectations of treatment effects [48]. We included a six-week waitlist arm to control for the possibility that AYAs' distress may change in the early post-treatment period.

Compared to an active (peer-support group) and a waitlist control, the primary outcome of this study was to measure the impact of Recapture Life on quality of life at six-weeks (end-of-treatment) and 12-months later. Given the preventative, resiliencefocused approach taken, the primary outcome of quality of life was designed to capture the potential for this support model to ameliorate the impact of cancer on a range of important facets of AYAs' psychosocial adjustment into early survivorship. Secondary outcome measures were:

1. Psychological outcomes: Depression and anxiety symptoms; 
2. Psychological processes/mechanisms: Coping skills, family functioning, cancerrelated identity;

3. Intervention delivery: Fidelity, group cohesion, and working (therapeutic) alliance;

4. Health economics: AYA real-world functioning (including engagement in productive activities such as work and study), health service use, and medication use, costs of delivering Recapture Life, and any averted travel costs for AYA participants.

This paper presents the Recapture Life RCT data addressing the primary and all secondary outcomes up to 12 months post-intervention.

\section{Materials and Methods}

\subsection{Study Design}

Figure 1 depicts our three-arm, phase II feasibility RCT design (Australian and New Zealand Clinical Trials Registry reference: ACTRN12610000717055). Our study had ethical approval from the South Eastern Sydney Local Health District (Reference HREC/12/POWH/136).

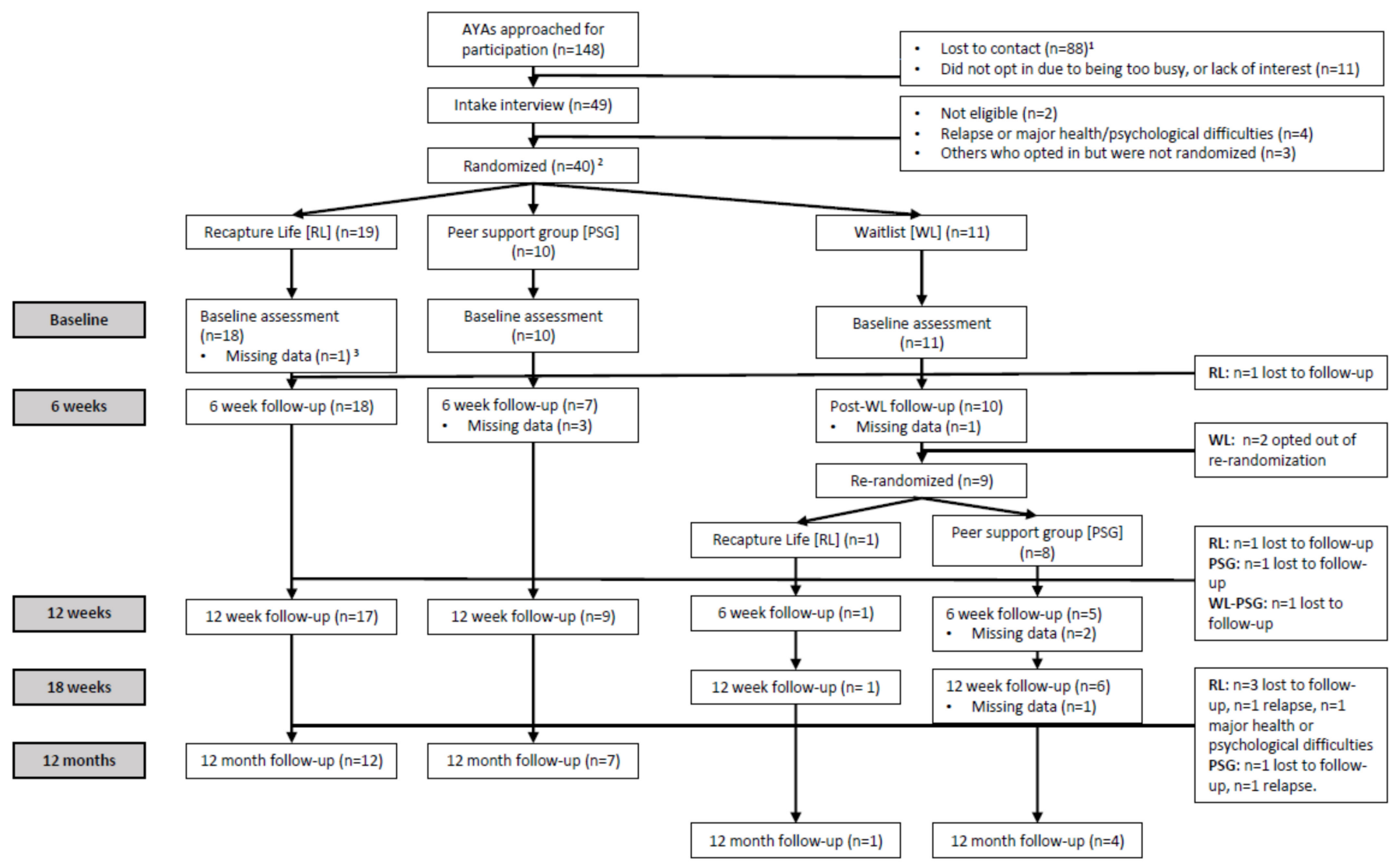

Abbreviations: RL - Recapture Life, PSG - peer support group, WL - waitlist. 'Participants not able to be successfully contacted following two attempted telephone calls, per our ethical approval. ${ }^{2}$ Due to the slower-than-expected pace of recruitment, we were unable to stratify randomization or group formation according to gender, age, distress, time since treatment or degree of rurality as per protocol. ${ }^{3} \mathrm{As}$ per CONSORT guidelines, missing data at each timepoint is displayed separately to the total number of complete participants with data, such that the total number of participants at each point is equal to the $n$ listed together with the missing data $n$.

Figure 1. CONSORT flowchart depicting recruitment across Recapture Life trial.

\subsubsection{Randomization and Blinding}

Randomization involved two separate algorithms, both generated by staff at the School of Psychology, UNSW (who were independent from the hospital-based research team). An algorithm was used to generate a random sequence $(n=15)$ of the three trial arms (Recapture Life, peer-support group, and waitlist), equally divided across the three arms. Groups of five consecutively recruited participants were allocated to each randomly-generated condition, before moving to the next with the subsequent group of five participants. This 
approach minimizes the waiting time for individual participants before an online group matching their allocation can be run with sufficient participant numbers, reducing drop-out and participant burden [49]. Waitlisted participants, at the conclusion of their waitlist, were re-randomized to receive either Recapture Life or the peer-support group, using a similar randomization algorithm at the group level. Re-randomized participants could be allocated to join online groups formed together with participants being randomized for the first time. Participants were blinded to their treatment allocation, however trial psychologists and research assistants could not be blinded due to the distinctness of intervention materials. Two psychologists facilitated groups across both arms (Recapture Life and peer-support group) to prevent any confounding of intervention- and psychologist-specific delivery factors.

\subsubsection{Sample Size and Power Calculation}

We calculated that a total sample size of 90 (assuming equal numbers in each group) would allow a medium-large effect size [50] of $d=0.65$ (calculated as the difference in change from T1 to T2 for any pair of groups, standardized on the pooled within-group standard deviation, and assuming a correlation between $\mathrm{T} 1$ and $\mathrm{T} 2$ of 0.6 ) on the primary outcome variable (QoL) to be detected with a power of $80 \%$ at a two-tailed significance level of 0.05. This clinically-significant [51] effect size was based on RCTs of similar interventions for AYAs with chronic illness [52-54] and online interventions targeted toward this age group [55]. Assuming a response rate of $50 \%$ and attrition rate of $20 \%$, which appeared feasible based on pilot work by our team, we originally anticipated that we would need to approach approximately 220 patients to achieve a final sample of 90 participants [56].

\subsubsection{Participants and Recruitment}

In line with Australian Youth Cancer Service definitions, eligible AYAs were defined as aged 15-25 years at the time of (curative) treatment completion and who finished treatment no more than 24 months ago. We recruited these participants through four pediatric and seven adult hospitals across Australia, as well as through three community organizations, via an invitation letter from their oncologist/local health-care professional. Collaborating site-specific clinicians were responsible for identifying eligible AYAs to invite from their site. AYAs were ineligible if they (i) did not speak adequate English (determined by either the need for clinical interpreters; or through AYA self-report during the intake process); (ii) demonstrated severe distress (e.g., active suicidality, psychosis, and/or extremely severe depression), or (iii) had an incurable cancer diagnosis.

Participating AYAs were also given the opportunity to invite any support person (e.g., parent, partner/spouse) over the age of 18 years to receive psycho-education about the intervention, to help them better support the young person and their engagement with the intervention. Support persons also completed questionnaires as part of the study

\subsection{Trial Arms}

\subsubsection{The Recapture Life Intervention}

The development of Recapture Life has been previously described in detail [43]. In brief, the online program involved six once-weekly 90-min small-group sessions involving 3-5 AYAs per group, facilitated by a psychologist, using online videoconferencing software (WebEx, by Cisco; San Jose, CA, USA). Each week, the group explored common cancer survivorship experiences, and relevant evidence-based CBT coping strategies. Participants were provided with a Recapture Life workbook containing psycho-educational content reflective of the online sessions, and home-practice activities to support mastery of the coping strategies discussed.

Participating support persons received a single telephone-based consultation with the psychologist facilitating their AYA's group, and weekly email updates of intervention content. As well as describing key session content, these updates provided generic examples of ways support persons could support the AYA and communicate about the weekly topic. Table 1 summarizes the content of Recapture Life and peer-support group programs. 
Table 1. Recapture Life and peer-support control group weekly content delivered by the psychologist during each module.

Module

Getting back into the swing of things after cancer

The 'elephant in the room': Thinking about the cancer coming back

Talking all things cancer: Simple communication skills for difficult situations

Goal-setting and planning for the future (even when things feel up in the air

\section{Recapture Life Program (Skills Focus)}

\section{Psycho-education \& normalization}

Discussion of range of common emotional and cognitive responses to cancer for individual and family. Building rapport and a safe, trusting group environment. Healthy balanced lives \& behavioral activation:

Discussion of impact of cancer on all areas of life including exercise, hobbies. Use of 'ACE' activity scheduling a to tackle 'inactivity trap' and help self-esteem/stress Positive activities scheduling to improve mood and increase sense of control.

$$
\mathrm{ABCD} \text { model \& thought challenging: }
$$

Introduction to $\mathrm{ABCD}$ model ${ }^{\mathrm{b}}$ and idea of 'unhelpful thinking styles'. Cognitive challenging. Identifying underlying beliefs about their cancer experience,

$$
\text { self and future. }
$$

Acceptance-based strategies:

Evaluating the usefulness of certain thoughts; thought suppression experiment; using worry postponement and other behavioral strategies to manage 'questions

$$
\text { without answers'. }
$$$$
\text { Social support: }
$$

Seeking out social support; managing unhelpful/difficult thoughts around friends/relationships; assertive communication skills. Strategies to reconnect with old friends and develop new friendships and relationships.

$$
\text { Goal setting: }
$$

Applying reappraisal and problem-solving skills to the future to develop realistic post-cancer goals. Psychological 'relapse' prevention: Anticipating future difficult situations and reviewing skills learnt to manage these situations in the future.

\section{Peer-Support Group (Discussion Topic)}

The cancer experience and coming off treatment. Common emotional responses to cancer for individual and family.

Impact of cancer on hobbies and lifestyles. Changes to routines, hobbies and activites.

How has cancer changed my family? Family reactions across the cancer trajectory, positive/challenging family supports

The big, 'scary' stuff: Niggling thoughts about illness, death and dying.

Discussing/normalizing existential and illness concerns.

Talking all things cancer and friends. Common social/friendship issues across the cancer trajectory; difficult topics to raise.

Moving on: Looking ahead to the future.

Normalizing uncertainty/change; discussing potential 'positives'; things to look forward towards.

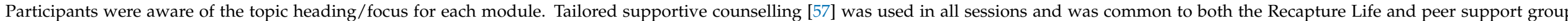

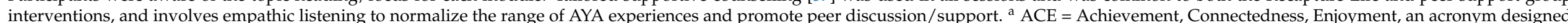

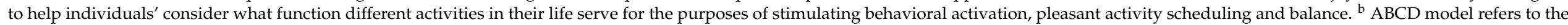

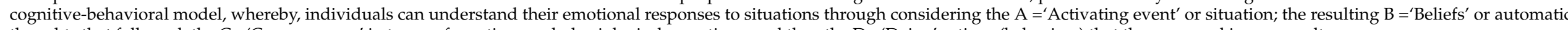
thoughts that followed, the $C={ }^{\prime}$ Consequences' in terms of emotions and physiological sensations, and then the $\mathrm{D}=$ 'Doing' actions (behaviors) that they engaged in as a result. 


\subsubsection{The Non-Directive, Peer-Support Group Control (Active Control)}

The peer-support group control matched Recapture Life in terms of frequency, type of contact and inclusion of support persons. However, instead of actively teaching and discussing CBT-related coping strategies, the peer-support group sessions focused on a different cancer-survivorship 'theme' each week, and involved an exclusive focus on non-directive, supportive group discussion between the AYA survivors [43].

\subsubsection{Waitlist}

AYAs randomized to waitlist completed the first baseline assessment, were waitlisted for six weeks, completed a repeat baseline assessment, and were then re-randomized to receive either Recapture Life or peer-support group at the conclusion of their waitlist period.

\subsection{Measures}

Self-reported measures were used to assess the impact of Recapture Life for both AYAs and support person participants, using online or paper-based questionnaires (according to participant preference), with additional detail previously published [43]. Table 2 details the administration schedule, scoring and psychometric properties for these measures in this population.

\subsubsection{Primary Outcome}

Quality of life. Five subscales from the Impact of Cancer Scale AYA module [58,59], assessed positive and negative impacts of cancer (Table 2). For all outcomes, higher subscale scores indicate a greater impact of cancer.

\subsubsection{Secondary Outcomes}

Psychological Outcomes

Depression and anxiety symptoms. We included the Depression, Anxiety and Stress Scale-Short Form [60] depression and anxiety subscales.

Psychological Mechanisms

Identity changes. We used the Centrality of Events Scale-Short Form [61], where a higher total score indicates that a stressful/traumatic life event is more central to a person's identity and life story. Participants also rated the extent to which they viewed themselves as either a cancer "patient" or "survivor" using a study-developed 10-point survivor identity visual analogue scale.

Unmet cancer-related needs. We used a subset of 17 items from the Cancer Needs Questionnaire for Parents/Carers of Adolescents and Young Adults with Cancer [62] to gauge support person unmet needs over time.

\section{Coping Strategies}

Positive and negative coping approaches. The KIDCOPE (Older version) [63] measured positive and negative adolescent coping approaches. A second study-developed scale assessed participants' CBT skills acquisition and use regarding 10 specific skills important in survivorship.

Family functioning. Both AYAs and support person participants completed three subscales of the McMaster Family Assessment Device [64].

Intervention Delivery Factors

Manual fidelity. Psychologist facilitators self-reported their fidelity to the Recapture Life manual following each session, and two blinded independent assessors also reviewed session recordings (Supplementary Data S1).

Working alliance. We used four items of the Working Alliance Inventory-Short Form [65].

Group cohesion. This was measured by four items from the validated California Psychotherapy Alliance Scale for Group [66]. 
Table 2. Assessment schedule for the Recapture Life study.

\begin{tabular}{|c|c|c|c|c|c|c|c|c|}
\hline \multirow[b]{2}{*}{ Domain Assessed } & \multirow[b]{2}{*}{ Measure and Subscale Information } & \multirow[b]{2}{*}{ Scoring and Analysis Information } & \multirow[b]{2}{*}{ Psychometric Validity Data Available } & \multicolumn{5}{|c|}{ Timepoint Administered } \\
\hline & & & & Intake & $\mathrm{T}^{\mathrm{a}}$ & $\begin{array}{c}\text { During } \\
\text { Intervention }\end{array}$ & $\mathrm{T} 2^{\mathrm{c}}$ & $\mathrm{T}^{\mathrm{d}}$ \\
\hline \multirow[b]{2}{*}{$\begin{array}{c}\text { Baseline } \\
\text { characteristics }\end{array}$} & \multirow{2}{*}{$\begin{array}{l}\text { Psychosocial Adjustment to Illness Scale-Interview form (PAIS) }{ }^{\text {e }} \\
\text { Demographic data }{ }^{*} \text { (AYAs' age, sex, level of educational attainment, } \\
\text { employment status, family structure, diagnosis, treatment regimen) } \\
\text { including six items from the Intensity of Treatment Rating Scale [68] }\end{array}$} & N/A & - & $\mathrm{x}$ & - & - & - & - \\
\hline & & N/A & - & - & $\mathrm{x}$ & - & - & - \\
\hline Quality of life & $\begin{array}{l}\text { Impact of Cancer Scale (IOCS): five subscales used included Social life } \\
\text { (negative), Uncertainties, worries and wonders (negative), Sense of } \\
\text { purpose/goals (positive), Identity (positive), Health behaviors (positive). } \\
\\
{ }^{\mathrm{f}} \text { Due to the younger age range of Australian AYAs relative to the US } \\
\text { validation cohort, in consultation with the scale's developer, we included } \\
55 \text { of the original } 91 \text { items [69]. }\end{array}$ & $\begin{array}{l}\text { 0 = strongly disagree) to } \\
\qquad 4=\text { strongly agree). } \\
\text { Following the method used by Zebrack } \\
\text { and Landier, [70] we calculated overall } \\
\text { positive and negative impacts by } \\
\text { summing items from positive and } \\
\text { negative subscales respectively. }\end{array}$ & $\begin{array}{l}\text { Validated in AYAs with cancer aged } \\
18-39, \text { good construct and concurrent } \\
\text { validity, and test-retest reliability [58,71] }\end{array}$ & - & $\mathrm{x}$ & - & $\mathrm{x}$ & $\mathrm{x}$ \\
\hline $\begin{array}{l}\text { Psychological } \\
\text { outcomes }\end{array}$ & $\begin{array}{l}\text { Depression, Anxiety, Stress Scales-short form (DASS-21): depression } \\
\text { (7 item) and anxiety ( } 7 \text { item) subscales }\end{array}$ & $\begin{array}{l}\text { 4-point scale, rating extent to which } \\
\text { they had experienced each symptom in } \\
\text { the past week }(1=\text { "Not at all" to } \\
4=\text { "Most of the time"). }\end{array}$ & $\begin{array}{c}\text { Australian adolescents [72] cancer } \\
\text { patients [73] strong internal consistency } \\
\text { and reliability }[72,74]\end{array}$ & $\mathrm{x}$ & $\mathrm{x}$ & - & $\mathrm{x}$ & $\mathrm{x}$ \\
\hline \multirow{4}{*}{$\begin{array}{l}\text { Psychological } \\
\text { mechanisms }\end{array}$} & Centrality of Events Scale-Short Form & $\begin{array}{l}\text { 5-point Likert scale to questions relating } \\
\text { to their cancer experience as a whole. } \\
\text { (range: } 7-35)\end{array}$ & $\begin{array}{l}\text { UK Young people aged } 8-18 \text { with } \\
\text { cancer [75] } \\
\text { Version of CES modified for cancer } \\
\text { survivors age } 13-23[76]\end{array}$ & - & $\mathrm{x}$ & - & $\mathrm{x}$ & $\mathrm{x}$ \\
\hline & $\begin{array}{l}\text { McMaster Family Assessment Device *-We administered the family } \\
\text { communication ( } 6 \text { items), problem-solving ( } 5 \text { items), and general } \\
\text { functioning (12 items) subscales in Recapture Life. }\end{array}$ & $\begin{array}{l}\text { from } 1 \text { to } 4 \text {, with the subscale score } \\
\text { calculated as the average of the item } \\
\text { scores, and higher scores indicating } \\
\text { more problematic functioning. }\end{array}$ & $\begin{array}{l}\text { US Adolescents (13-19) currently } \\
\text { undergoing treatment [77] US } \\
\text { adolescents (11-19) post-treatment [78] }\end{array}$ & - & $\mathrm{x}$ & - & $\mathrm{x}$ & $\mathrm{x}$ \\
\hline & $\begin{array}{l}\text { KIDCOPE-Older Version: Respondents name a recent cancer-related } \\
\text { problem and rate } 8 \text { coping strategies for frequency of use (“Did you do } \\
\text { this?"), and efficacy (“Did it help?"). } \\
\text { Measures positive (e.g., social support, cognitive restructuring) and } \\
\text { negative (e.g., resignation, social withdrawal) }\end{array}$ & $\begin{array}{l}\text { Frequency was measured as a binary } \\
\text { response (“Yes" /“No") and efficacy } \\
\text { was measured on a 3-point scale (“Not } \\
\text { at all”/“"A little”/“A lot"). }\end{array}$ & \multirow[t]{2}{*}{ US adolescents (12-18) with cancer [79] } & - & $\mathrm{x}$ & - & $\mathrm{x}$ & $\mathrm{x}$ \\
\hline & $\begin{array}{c}\text { Cognitive-behavior therapy (CBT) skills (study-developed): Assessing } \\
\text { participants' acquisition of CBT skills, e.g., identifying thoughts/feelings } \\
\text { in response to cancer treatment, and recognizing circular ruminative } \\
\text { thinking processes }\end{array}$ & $\begin{array}{l}\text { Participants were asked to rate their } \\
\text { confidence ("since the online group } \\
\text { program sessions, ... did you feel like } \\
\text { you could ..." (Yes/No)) and their } \\
\text { actual use of each skill ("did you } \\
\text { actually do...?" } \\
\text { (Not at all/A little/A lot)) }\end{array}$ & & - & $\mathrm{x}$ & - & $\mathrm{x}$ & $\mathrm{x}$ \\
\hline $\begin{array}{l}\text { Support person } \\
\text { outcomes }\end{array}$ & $\begin{array}{l}\text { Cancer Needs Questionnaire for Parents/Carers (CNQ-PC) }: 17 \text { items g } \\
\text { addressed their relationship with the AYA, their ability to communicate, } \\
\text { changes in relationships and friendships, and worries about the AYA's } \\
\text { cancer returning. These cancer needs were addressed in the Recapture } \\
\text { Life support person emails. }\end{array}$ & $\begin{array}{l}\text { 5-point rating scale, with options } \\
\text { ranging from "no need" to } \\
\text { "very high need" }\end{array}$ & - & - & $\mathrm{x}$ & - & $\mathrm{x}$ & $\mathrm{x}$ \\
\hline
\end{tabular}


Table 2. Cont.

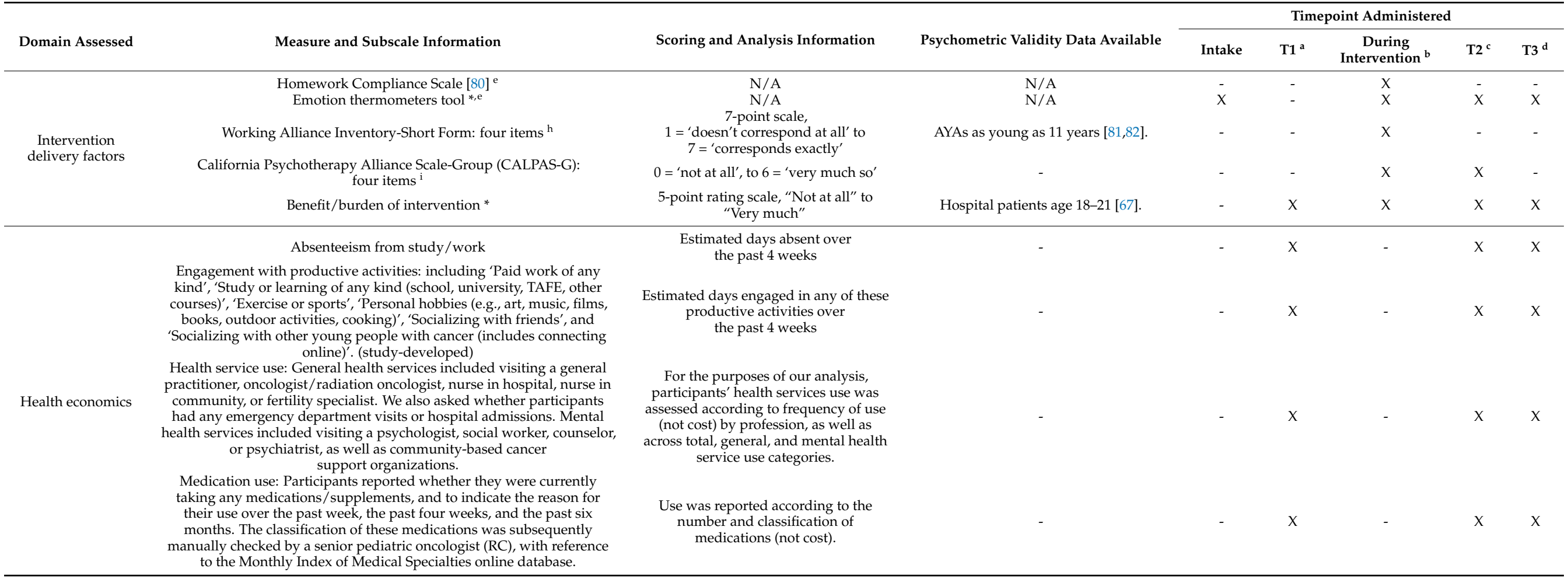

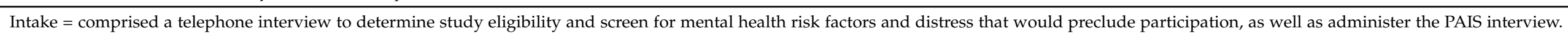



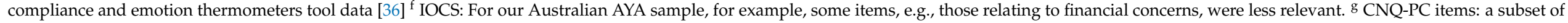

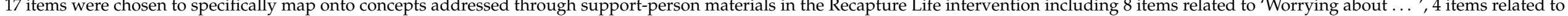

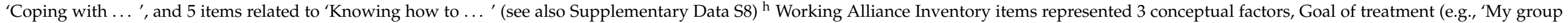

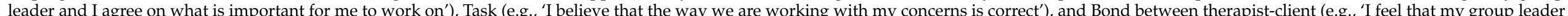

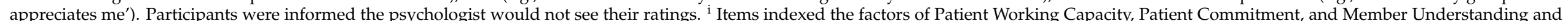
Involvement from the overall scale. * Measures with an asterisk also used in support-person participants at these same time-points. ^ Measure given only to support-person participants. 
Benefit and burden of program. Two validated items [67] assessed perceived benefit and burden of participating in the study. Additional free-text comments were optional.

Health Economics Outcomes: Cost and Real-World Functioning (Study-Developed Items)

Real-world functioning. Two items asked AYAs/support persons' general functioning through engagement in, and absenteeism from, real-world activities.

Health, mental health service, and medication use. Participants reported whether they had used a range of health services over the past six months. Participants also reported whether they were currently taking any medications/supplements, and to indicate the reason for their use.

Cost. (i) Cost of delivery. We calculated the cost of delivering Recapture Life by analyzing a detailed log of all participant clinical contacts (both number and duration) relevant to the appropriate clinical delivery of the program during the trial. The costs used reflected the level of expertise appropriate for the delivery of the intervention, across a range of clinical-academic settings (Supplementary Data S2).

(ii) Estimated travel costs saved for AYAs. We also estimated travel costs averted for our Recapture Life AYA participants by calculating the estimated additional costs that would have been borne by participants if they had to travel to their local hospital site to attend a similar number of intervention sessions as in Recapture Life (Supplementary Data S2).

\subsection{Data Analysis}

We used R version 3.6.0 [88] to perform all analyses. Descriptive statistics were used to summarize participant characteristics. Abiding by the intention-to-treat principle [89], we performed comparisons between trial arms in two ways: Changes between baseline and the 6-week follow-up were compared across all three groups (three-way analyses: examining outcomes across Recapture Life, peer-support group control, and waitlist control), while changes over the 12-month follow-up period were compared between the Recapture Life and peer-support arms, with waitlisted participants analyzed according to the active treatment arm on which they were re-randomized, and their outcomes at the post-waitlist follow-up being used as their baseline (two-way analyses).

For comparisons of continuous outcomes (impact of cancer, depression, anxiety, centrality of events and family functioning), we used the nlme package [90] to fit linear mixed effects models with individual-specific intercepts and a continuous AR(1) residual structure, and employed likelihood ratio tests to assess the differences between arms in average changes over time, accounting for baseline. For other outcomes, we used the lme4 [91] and ordinal [92] packages to fit generalized linear mixed effects models similar to the linear mixed model previously described. We used binomial logistic (coping strategies, CBT skills, unmet cancer needs, health service use), ordinal logistic (benefit, burden, survivor identity), or log-link Poisson (number of emergency department visits, nights in hospital) models, as appropriate. Fitted values and their $95 \%$ confidence intervals from each model were produced using the emmeans package [93]. These post-hoc exploratory analyses are typically underpowered, and non-significant results in these analyses does not necessarily mean there is no effect.

In order to better understanding whether particular subgroups of AYAs responded differently to the two online interventions, we also undertook several post-hoc exploratory moderation analyses to examine whether three key participant factors (age, sex, and time since treatment-completion) were associated with differences between arms in the primary outcome of interest (Impact of Cancer), as well as depression and anxiety symptoms. We did this by extending our mixed-effects models and performing likelihood ratio tests on three-way interactions between trial arm, time point and each characteristic of interest.

In cases where the outcome variable did not have a simple parametric distribution (days off work/study, days engaged with productive activities), we performed nonparametric Kruskal-Wallis rank sum tests on the changes from baseline at each time point. 
We used Chi-squared tests for simple comparisons of post-baseline relapses and manual fidelity between arms.

\section{Results}

\subsection{Participants}

Our final sample included 40 AYAs (27\% of the 148 AYAs invited; $89 \%$ of 45 AYAs who opted-in), and 18 support persons (Figure 1) [36]. Our sample was ultimately recruited from April 2012-August 2015 from 10 sites; four hospitals ( 2 adult, 2 pediatric) did not recruit any participants $[36,94]$. The trial was stopped due to the project's funding ending. Using the assumptions of our original power calculations, this final sample gave us $30 \%$ power to detect differences between waitlist and peer-support control arms, and 43\% between waitlist and Recapture Life arms.

As previously published [36], the AYAs had a mean age of 20.6 years (SD $=3.0$, median = 20 years, range: 15-26), had finished cancer treatment an average of 8 months previously ( $\mathrm{SD}=4.7$ months; median $=7$, range: $1-19$ ) and were balanced by gender (female: $n=21,52 \%$ ). Half of the sample had been diagnosed with a hematological malignancy $(n=20,50 \%)$. We have previously reported clinical challenges experienced during the trial [34], and while no harmful or adverse events occurred as a result of the trial or intervention, at study close, four participants $(11.8 \%)$ reported a confirmed relapse (from intake to 12-month follow-up). Participants lived on average $82 \mathrm{~km}$ from their nearest capital city $(\mathrm{SD}=124 \mathrm{~km}$; median $=17$; range $=3.8-429)$. Two-thirds of support persons were mothers $(n=12,67 \%)$. Support persons had a mean age of 43.9 years $(\mathrm{SD}=11.9$, median $=49$, range: $21-59$ ). Table 3 depicts participant characteristics by RCT arm. Our 11 online groups mostly comprised a mix of AYA ages and genders (see Supplementary Data S3 for detail on group composition).

Most of our AYA sample $(34,91.9 \%)$ reported never having consulted mental health professionals prior to their cancer diagnosis (including psychologists, social workers, counsellors, or psychiatrists). However, over one-third ( $n=14,38.0 \%$ ) reported having consulted mental health professionals at any time since their diagnosis, and prior to the study's baseline

\subsection{Primary Outcome: Impact of Cancer on Quality of Life}

As noted above, we undertook three-way analyses (Recapture Life vs. peer-support group control vs. waitlist control at 6 weeks post-intervention) and two-way analyses (Recapture Life vs. peer-support group control 12-month post-intervention).

\subsubsection{Positive and Negative Impact of Cancer}

No evidence of differences emerged between Recapture Life, peer-support group control, or waitlist control on AYAs' perceptions of either the positive (all $p$-values $\geq 0.46$ ) or negative ( $p$-values $\geq 0.14$ ) impact of cancer over the 6-week intervention period (see Supplementary Data S4)

However, Recapture Life participants reported higher perceptions of experiencing an overall negative impact of cancer (difference $=0.53,95 \% \mathrm{CI}=(0.03-1.03), p=0.038)$ and impact on the cancer-related uncertainties subscale than peer-support group participants at 12 months post-intervention (difference $=0.67,95 \% \mathrm{CI}=(0.17-1.17), p=0.009$; Figure 2).

\subsubsection{Post-Hoc Moderation Analyses}

Neither age nor time since cancer treatment-completion appeared to impact AYAs' impact of cancer scores. However, post-hoc analyses provided some evidence suggesting that the positive impact of cancer differed with age, though this did not reach significance $\left(F_{(1,48)}=2.88, p=0.096\right)$; younger AYAs allocated to Recapture Life reported higher positive impact of cancer compared to peer support group control, with little difference between treatment arms for older AYAs (Supplementary Data S5). 
Table 3. Participant demographics by trial arm.

\begin{tabular}{|c|c|c|c|c|}
\hline & Waitlist $(n=11$ ) & PSG $(n=10)$ & RL $(n=19)$ & Total $(N=40)$ \\
\hline \multicolumn{5}{|c|}{ Sex } \\
\hline Male, n (\%) & $6(55)$ & $5(50)$ & $8(42)$ & $19(48)$ \\
\hline Female, n (\%) & $5(45)$ & $5(50)$ & $11(58)$ & $21(52)$ \\
\hline \multicolumn{5}{|c|}{ Participant age $(n=38)^{\wedge}$} \\
\hline Mean (SD) & $20.9(3.1)^{\wedge}$ & $22.5(2.5)$ & $19.4(2.6)^{\wedge}$ & $20.6(3.0)^{\wedge}$ \\
\hline Median (IQR) & $20.0(18.2,23.8)^{\wedge}$ & $23.0(20.8,23.8)$ & $19.0(18.0,20.0)^{\wedge}$ & $20.0(18.0,23.0)^{\wedge}$ \\
\hline Range & $17-26$ & $18-26$ & $15-25$ & $15-26$ \\
\hline \multicolumn{5}{|c|}{ Highest education attained } \\
\hline Year 10 or below, n (\%) & $2(18)$ & $0(0)$ & $4(21)$ & $6(15)$ \\
\hline Year $12, \mathrm{n}(\%)$ & $3(27)$ & $5(50)$ & $10(53)$ & $18(45)$ \\
\hline Apprenticeship, n (\%) & $0(0)$ & $1(10)$ & $2(11)$ & $3(8)$ \\
\hline TAFE or certificate/diploma, college, n (\%) & $2(18)$ & $1(10)$ & $1(5)$ & $4(10)$ \\
\hline University degree, $\mathrm{n}(\%)$ & $4(36)$ & $3(30)$ & $1(5)$ & $8(20)$ \\
\hline \multicolumn{5}{|c|}{ Participant employment status } \\
\hline Employed: Full-time, part-time or casual, n (\%) & $6(55)$ & $7(70)$ & $8(42)$ & $21(53)$ \\
\hline Unemployed: Student, $\mathrm{n}(\%)$ & $2(18)$ & $1(10)$ & $7(37)$ & $10(25)$ \\
\hline Unemployed: Non-student, n (\%) & $3(27)$ & $2(20)$ & $3(16)$ & $8(20)$ \\
\hline \multicolumn{5}{|c|}{ Distance from nearest capital city (km) } \\
\hline Mean (SD) & $113(177)$ & $71(90)$ & $69(106)$ & $82(124)$ \\
\hline Median (IQR) & $11(8,207)$ & $20(10,102)$ & $18(9,78)$ & $17(8,97)$ \\
\hline Range & $3.8-389$ & $5.2-275$ & $4.9-429$ & $3.8-429$ \\
\hline ARIA classification $^{1}$ & & & & \\
\hline Major city, n (\%) & $8(73)$ & $8(80)$ & $12(63)$ & $28(70)$ \\
\hline Inner regional, $\mathrm{n}(\%)$ & $3(27)$ & $1(10)$ & $5(26)$ & $9(22)$ \\
\hline Outer regional, n (\%) & $0(0)$ & $1(10)$ & $2(11)$ & $3(8)$ \\
\hline \multicolumn{5}{|c|}{ Aboriginal and/or Torres Strait Islander } \\
\hline No, n (\%) & $10(91)$ & $10(100)$ & $18(95)^{\wedge}$ & $38(95)^{\wedge}$ \\
\hline Yes, Aboriginal, n (\%) & $1(9)$ & $0(0)$ & $0(0)^{\wedge}$ & $1(2)^{\wedge}$ \\
\hline \multicolumn{5}{|c|}{ Speaks language(s) other than English at home } \\
\hline No, n (\%) & $9(82)$ & $10(100)$ & $15(79)^{\wedge}$ & $34(85)^{\wedge}$ \\
\hline Yes, n (\%) & $2(18)$ & $0(0)$ & $3(16)^{\wedge}$ & $5(12)^{\wedge}$ \\
\hline \multicolumn{5}{|c|}{ Country of birth } \\
\hline Australia, n (\%) & $9(82)$ & $10(100)$ & $17(89)$ & $36(90)$ \\
\hline Other, $\mathrm{n}(\%)$ & $2(18)$ & $0(0)$ & $2(11)$ & $4(10)$ \\
\hline \multicolumn{5}{|c|}{ Age at cancer diagnosis } \\
\hline Mean (SD) & $19.4(4.0)$ & $21.2(2.9)$ & $17.8(2.4)$ & $19.1(3.3)$ \\
\hline Median (IQR) & $20.0(17.0,22.5)$ & $21.5(19.5,22.8)$ & $17.5(16.2,19.5)$ & $18.0(17.0,21.5)$ \\
\hline Range & $11-25$ & $16-25$ & $13-23$ & $11-25$ \\
\hline \multicolumn{5}{|c|}{ Cancer type } \\
\hline Blood, n (\%) & $6(55)$ & $4(40)$ & $10(53)$ & $20(50)$ \\
\hline Solid tumor, n (\%) & $4(36)$ & $4(40)$ & $9(47)$ & $17(42)$ \\
\hline Brain, n (\%) & $1(9)$ & $2(20)$ & $0(0)$ & $3(8)$ \\
\hline \multicolumn{5}{|c|}{ Cancer stage at diagnosis } \\
\hline Stage $1, \mathrm{n}(\%)$ & $1(9)$ & $4(40)$ & $1(5)$ & $6(15)$ \\
\hline Stage $2, \mathrm{n}(\%)$ & $3(27)$ & $2(20)$ & $3(16)$ & $8(20)$ \\
\hline Stage 3, n (\%) & $1(9)$ & $1(10)$ & $2(11)$ & $4(10)$ \\
\hline Stage $4, \mathrm{n}(\%)$ & $4(36)$ & $1(10)$ & $3(16)$ & $8(20)$ \\
\hline Unsure, n (\%) & $1(9)$ & $1(10)$ & $7(37)$ & $9(22)$ \\
\hline \multicolumn{5}{|c|}{ Cancer risk level } \\
\hline Standard, n (\%) & $2(18)$ & $0(0)$ & $3(16)$ & $5(12)$ \\
\hline Low, n (\%) & $2(18)$ & $1(10)$ & $0(0)$ & $3(8)$ \\
\hline Intermediate, $\mathrm{n}(\%)$ & $2(18)$ & $2(20)$ & $5(26)$ & $9(22)$ \\
\hline High, n (\%) & $2(18)$ & $2(20)$ & $6(32)$ & $10(25)$ \\
\hline Unsure, n (\%) & $3(27)$ & $5(50)$ & $4(21)$ & $12(30)$ \\
\hline \multicolumn{5}{|c|}{ Treatment(s) received } \\
\hline Surgery, n (\%) & $8(73)$ & $7(70)$ & $10(53)$ & $25(62)$ \\
\hline Chemotherapy, n (\%) & $10(91)$ & $8(80)$ & $17(89)$ & $35(88)$ \\
\hline Radiotherapy, n (\%) & $6(55)$ & $2(20)$ & $5(26)$ & $13(32)$ \\
\hline BMT, n (\%) & $1(9)$ & $1(10)$ & $4(21)$ & $6(15)$ \\
\hline
\end{tabular}


Table 3. Cont.

\begin{tabular}{|c|c|c|c|c|}
\hline & Waitlist $(n=11$ ) & PSG $(n=10)$ & RL $(n=19)$ & Total $(N=40)$ \\
\hline \multicolumn{5}{|c|}{ Intensity of Treatment Rating ${ }^{2}$} \\
\hline $1, \mathrm{n}(\%)$ & $0(0)$ & $1(10)$ & $1(5)$ & $2(5)$ \\
\hline $2, \mathrm{n}(\%)$ & $4(36)$ & $3(30)$ & $5(26)$ & $12(30)$ \\
\hline $3, \mathrm{n}(\%)$ & $7(64)$ & $5(50)$ & $10(53)$ & $22(55)$ \\
\hline $4, \mathrm{n}(\%)$ & $0(0)$ & $0(0)$ & $2(11)$ & $2(5)$ \\
\hline (Missing), n (\%) & $0(0)$ & $1(10)$ & $1(5)$ & $2(5)$ \\
\hline \multicolumn{5}{|c|}{ Months since treatment completion } \\
\hline Mean (SD) & $8.0(5.5)$ & $6.4(4.0)$ & $9.1(4.7)$ & $8.0(4.7)$ \\
\hline Median (IQR) & $6(6,9)$ & $6(4,10)$ & $9(6,12)$ & $7(5,12)$ \\
\hline Range & $2-19$ & $1-12$ & $2-18$ & $1-19$ \\
\hline \multicolumn{5}{|c|}{ Disease progression } \\
\hline On-trial relapses, n (\%) & - & $2(11.1)$ & $2(12.5) *$ & $4(11.7)$ \\
\hline Overall relapses, n (\%) & - & $3(18.8) * *$ & $6(40.0) * * *$ & $9(29)$ \\
\hline Deaths ${ }^{3}$ & - & $1(10)$ & $4(21)$ & $5(12.5)$ \\
\hline \multicolumn{5}{|c|}{ Self-rated health } \\
\hline Excellent, n (\%) & $3(27)$ & $0(0)$ & $3(16)$ & $6(15)$ \\
\hline Very good, n (\%) & $3(27)$ & $4(40)$ & $7(37)$ & $14(35)$ \\
\hline Good, n (\%) & $2(18)$ & $5(50)$ & $5(26)$ & $12(30)$ \\
\hline Fair, n (\%) & $3(27)$ & $1(10)$ & $3(16)$ & $7(18)$ \\
\hline Poor, n (\%) & $0(0)$ & $0(0)$ & $0(0)$ & $0(0)$ \\
\hline Unknown, n (\%) & $0(0)$ & $0(0)$ & $1(5)$ & $1(2)$ \\
\hline \multicolumn{5}{|c|}{ Pre-diagnosis mental health service use ${ }^{4}$} \\
\hline Yes, n (\%) & $3(27)$ & $4(40)$ & $10(53)$ & $17(42)$ \\
\hline No, n (\%) & $8(73)$ & $6(60)$ & $8(42)$ & $22(55)$ \\
\hline (Missing), n (\%) & $0(0)$ & $0(0)$ & $1(5)$ & $1(2)$ \\
\hline \multicolumn{5}{|c|}{ Parents' marital status } \\
\hline Separated or divorced, $\mathrm{n}(\%)$ & $5(45)$ & $5(50)$ & $7(37)$ & $17(42)$ \\
\hline Not separated or divorced, $\mathrm{n}(\%)$ & $6(55)$ & $5(50)$ & $11(58)$ & $22(55)$ \\
\hline \multicolumn{5}{|c|}{ Support person relationship } \\
\hline Mother, n (\%) & $4(36)$ & $4(40)$ & $4(21)$ & $12(30)$ \\
\hline Father, n (\%) & $0(0)$ & $0(0)$ & $1(5)$ & $1(2)$ \\
\hline Spouse/Partner, n (\%) & $1(9)$ & $2(20)$ & $0(0)$ & $3(8)$ \\
\hline Other/Unknown, n (\%) & $0(0)$ & $1(10)$ & $1(5)$ & $2(5)$ \\
\hline (No support person), $\mathrm{n}(\%)$ & $6(55)$ & $3(30)$ & $13(68)$ & $22(55)$ \\
\hline \multicolumn{5}{|l|}{ Support person age ${ }^{\wedge}$} \\
\hline Mean (SD) & $46.4(13.3)$ & $38.0(12.9)$ & $49.8(4.8)$ & $43.9(11.9)$ \\
\hline Range & $24-59$ & $21-53$ & $43-56$ & $21-59$ \\
\hline
\end{tabular}

$\mathrm{RL}=$ Recapture Life, PSG = Peer-support group, BMT = Bone marrow transplant, SD = Standard deviation; IQR = Inter-quartile range. ^denotes some variables missing for some participants due to a missing response for some items. ^ denotes some variables missing for some items. ${ }^{*}$ of $16 ; \mathrm{n}=4$ missing. ${ }^{* *}$ of $16, \mathrm{n}=2$ missing. ${ }^{* * *}$ of $15, \mathrm{n}=5$ missing. ${ }^{1}$ The Accessibility/Remoteness Index of Australia (ARIA) is a standardized classification and index of remoteness from service centers [95]. ${ }^{2}$ The Intensity of Treatment Rating (ITR-3) is a reliable and valid scale for classifying pediatric oncology treatment protocols [68]. ${ }^{3}$ Of these deaths, four were related to cancer and one was unrelated. ${ }^{4}$ From psychologists, psychiatrists, counsellors or social workers.

\subsection{Secondary Outcomes}

\subsubsection{Psychological Outcomes: Depression and Anxiety Symptoms}

On average, participants across groups reported mean scores reflecting depression and anxiety symptoms in the normal range of the DASS-21 at each trial time point (Table 4). Three-way analyses showed no evidence that either Recapture Life or peer-support group participants differed to waitlist controls on depression or anxiety symptoms at the 6-week follow-up ( $p$ 's > 0.30). Focusing just on the two online interventions, adjusting for baseline, individuals allocated to Recapture Life had higher levels of anxiety at 12-weeks $(p=0.046)$, and 12-months post-intervention $(p=0.041)$, and higher levels of depression at 12-months $(p=0.041)$, compared to those in the peer-support group (Figure 3$)$. There was no evidence that either intervention had differential effects according to an individual's baseline depression or anxiety scores ( $p$-values $\geq 0.092$ ). 


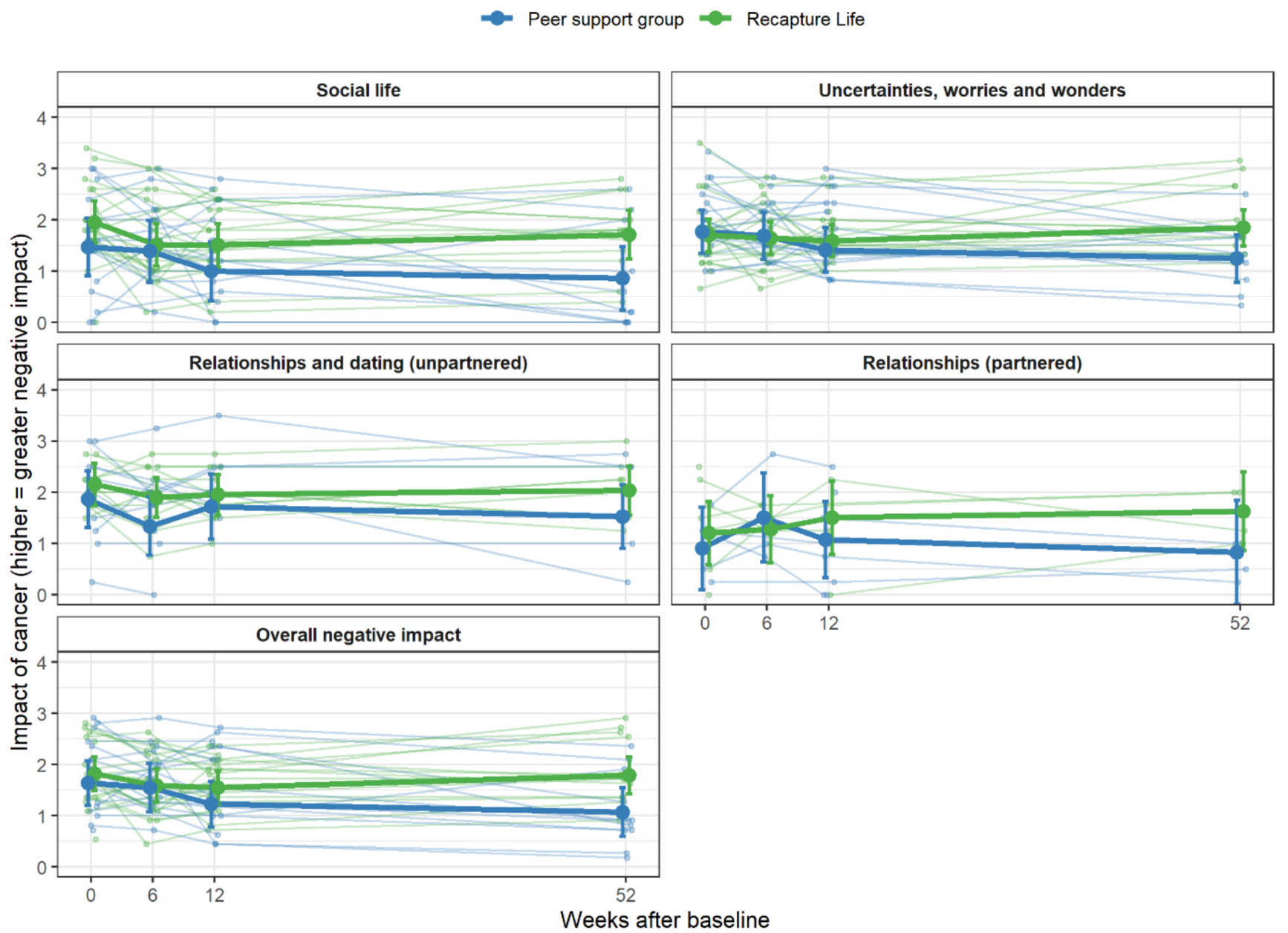

Figure 2. Differences between Recapture Life and peer-support group on negative impact of cancer, over time. Note. Individual scores are displayed, overlaid with thicker lines showing group-specific means and 95\% confidence intervals. Three-way analyses comparing Recapture Life, peer-support group and waitlist are depicted in Supplementary Data S4).

Table 4. Outcome measures * by intervention arm across timepoints.

\begin{tabular}{|c|c|c|c|c|}
\hline & & 6 Weeks & 12 Weeks & 12 Months \\
\hline \multicolumn{5}{|c|}{ AYA Outcomes } \\
\hline \multirow[t]{2}{*}{ High perceived benefit ${ }^{a}-n(\%)$} & PSG & - & $8(53.3)$ & $7(64.0)$ \\
\hline & RL & - & $12(67.0)$ & $9(75.0)$ \\
\hline \multirow{2}{*}{ Low burden $\ddagger-n(\%)$} & PSG & - & $14(93.3)$ & $10(91.0)$ \\
\hline & RL & - & $16(88.9)$ & $10(83.3)$ \\
\hline \multicolumn{5}{|c|}{ Psychological outcomes } \\
\hline \multirow[t]{2}{*}{ DASS-21 Depression ${ }^{1}$ M (95\% CI) } & PSG & $4.4(-0.7,+9.5)$ & $2.6(-2.0,7.3)$ & $1.7(-3.5,6.8)$ \\
\hline & RL & $4.0(0.7,7.4)$ & $4.5(1.1,7.9)$ & $5.8(1.8,9.7)$ \\
\hline \multirow[t]{2}{*}{ DASS-21 Anxiety ${ }^{1} \mathrm{M}(95 \% \mathrm{CI})$} & PSG & $4.3(0.3,8.2)$ & $2.7(-1.0,6.5)$ & $2.8(-1.3,7.0)$ \\
\hline & RL & $5.3(2.6,8.0)$ & $4.3(1.5,7.1)$ & $5.4(2.2,8.6)$ \\
\hline \multicolumn{5}{|c|}{ Mechanisms and process variables } \\
\hline \multirow[t]{2}{*}{ Centrality of Events ^ } & PSG & $26.09(23.41,28.78)$ & $26.02(23.48,28.56)$ & $27.99(25.22,30.77)$ \\
\hline & RL & $26.28(24.44,28.12)$ & $25.38(23.51,27.25)$ & $27.48(25.37,29.60)$ \\
\hline \multirow[t]{2}{*}{ Survivor label } & PSG & $6.4(5.0,7.9)$ & $7.3(6.1,8.6)$ & $6.9(5.4,8.3)$ \\
\hline & RL & $7.5(6.6,8.4)$ & $8.2(7.4,9.1)$ & $8.0(7.0,9.0)$ \\
\hline \multirow[t]{2}{*}{ KIDCOPE—strategies used } & PSG & $5.8(4.6,6.6)$ & $4.3(3.2,5.3)$ & $4.5(3.2,5.6)$ \\
\hline & RL & $6.3(5.7,6.8)$ & $5.8(5.1,6.5)$ & $6.0(5.1,6.7)$ \\
\hline KIDCOPE—strategies that helped & PSG & $5.0(3.9,6.0)$ & $4.4(3.3,5.4)$ & $4.1(2.9,5.3)$ \\
\hline
\end{tabular}


Table 4. Cont.

\begin{tabular}{|c|c|c|c|c|}
\hline & & 6 Weeks & 12 Weeks & 12 Months \\
\hline \multirow{2}{*}{$\begin{array}{c}\text { CBT skills—confidence, } \mathrm{M}(95 \% \\
\text { CI })\end{array}$} & RL & $5.7(5.0,6.3)$ & $5.3(4.6,5.9)$ & $5.2(4.3,5.9)$ \\
\hline & PSG & $8.8(7.19 .5)$ & $9.1(7.7,9.6)$ & $8.6(6.8,9.5)$ \\
\hline \multirow{3}{*}{ CBT skills-actual use M (95\% CI) } & RL & $9.7(9.0,9.9)$ & $9.8(9.4,9.9)$ & $9.7(8.9,9.9)$ \\
\hline & PSG & $7.2(5.5,8.4)$ & $8.2(6.9,9.0)$ & $8.0(6.4,9.0)$ \\
\hline & RL & $9.3(8.7,9.7)$ & $9.1(8.2,9.5)$ & $9.1(8.2,9.6)$ \\
\hline \multicolumn{5}{|c|}{ Family Functioning \# } \\
\hline \multirow[t]{2}{*}{ General functioning } & PSG & $1.81(1.50,2.12)$ & $1.91(1.62,2.21)$ & $1.92(1.60,2.23)$ \\
\hline & RL & $1.97(1.76,2.19)$ & $2.05(1.83,2.27)$ & $2.00(1.77,2.24)$ \\
\hline \multirow[t]{2}{*}{ Communication } & PSG & $2.32(2.04,2.60)$ & $2.13(1.87,2.39)$ & $2.15(1.87,2.42)$ \\
\hline & RL & $2.24(2.05,2.43)$ & $2.23(2.03,2.42)$ & $2.19(1.98,2.40)$ \\
\hline \multirow[t]{2}{*}{ Problem-solving } & PSG & $2.26(1.95,2.58)$ & $2.19(1.88,2.50)$ & $2.31(1.96,2.66)$ \\
\hline & RL & $2.25(2.03,2.48)$ & $2.16(1.94,2.39)$ & $2.07(1.81,2.34)$ \\
\hline \multicolumn{5}{|c|}{ Support person outcomes } \\
\hline \multirow[t]{2}{*}{ High perceived benefit ${ }^{a}-n(\%)$} & PSG & $1(20.0)$ & $2(25.0)$ & $0(0)$ \\
\hline & RL & $5(83.3)$ & $3(50.0)$ & $1(14.3)$ \\
\hline \multirow[t]{2}{*}{ Low burden $\ddagger-n(\%)$} & PSG & $6(100)$ & $8(100)$ & $5(100)$ \\
\hline & RL & $5(83.3)$ & $4(100)$ & $6(100)$ \\
\hline \multicolumn{5}{|c|}{ Cancer Needs Questionnaire for Parents/Carers } \\
\hline \multirow[t]{2}{*}{ Number of high/very high needs } & PSG & $0.6(0.1,4.8)$ & $1.0(0.2,3.9)$ & $0.7(0.1,4.0)$ \\
\hline & RL & $2.4(0.6,7.0)$ & $0.2(0.0,1.1)$ & $1.0(0.2,3.7)$ \\
\hline
\end{tabular}

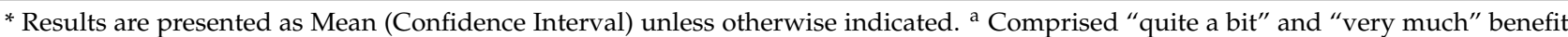
ratings.ł Comprised "not at all" and "a little bit" burden ratings. ${ }^{1}$ NB: Scores 0-9 are in the Normal range for DASS-21 Depression, and scores $0-7$ in the normal range for DASS-21 Anxiety subscales. ${ }^{\wedge}$ CES scores-A higher total score indicates higher event centrality (range: 7 to 35). \# McMaster Family Assessment Device: Clinical cut-off for the subscales were 2.0 for the general family functioning subscale, 2.2 for the problem solving subscale and 2.2 for the communication subscale [96,97]. Some data were missing for some participants.

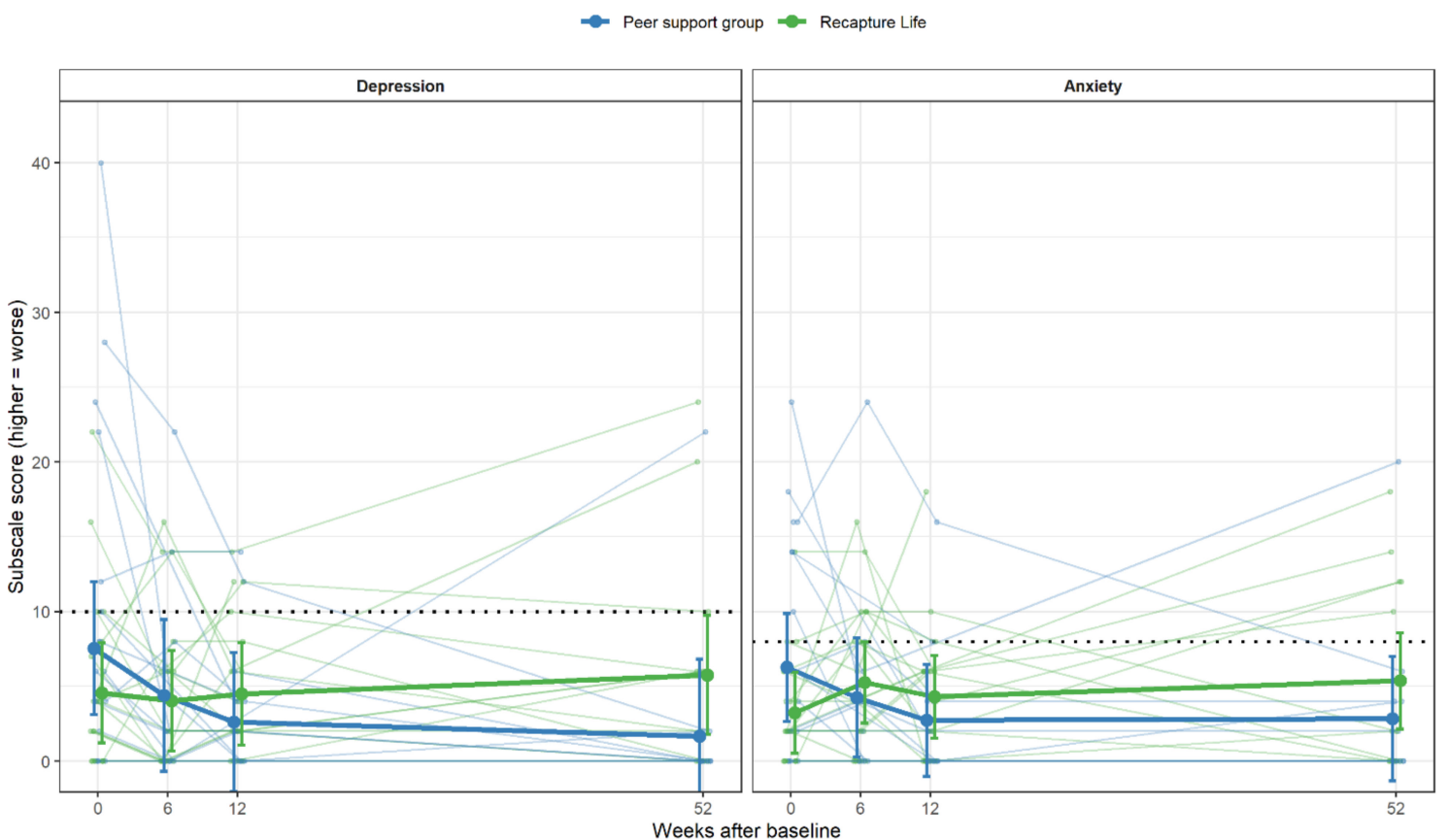

Figure 3. Depression and anxiety symptoms between Recapture Life and peer-support groups over time. Note. Individual scores are displayed, overlaid with thicker lines showing group-specific means and $95 \%$ confidence intervals. Dotted line indicates the upper end of 'Normal' range of symptoms on each subscale, with scores above this indicating Mild symptoms and above. 
Post-hoc moderation analyses. Neither AYAs' age nor sex moderated their scores on depression or anxiety in response to either intervention. However, evidence suggested that AYAs' time since treatment-completion moderated the impact of the intervention on anxiety symptoms $\left(F_{(1,48)}=5.52, p=0.023\right)$, but not depression $(p=0.10)$. These analyses suggested that the peer-support group intervention yielded better improvements in anxiety outcomes for AYAs closer to treatment completion, and that these participants gained more of this advantage over time (up to the 12-month follow-up). For AYAs further into survivorship post-treatment, Recapture Life appeared relatively more beneficial than the peer-support group in improving anxiety symptoms (Figure 4).

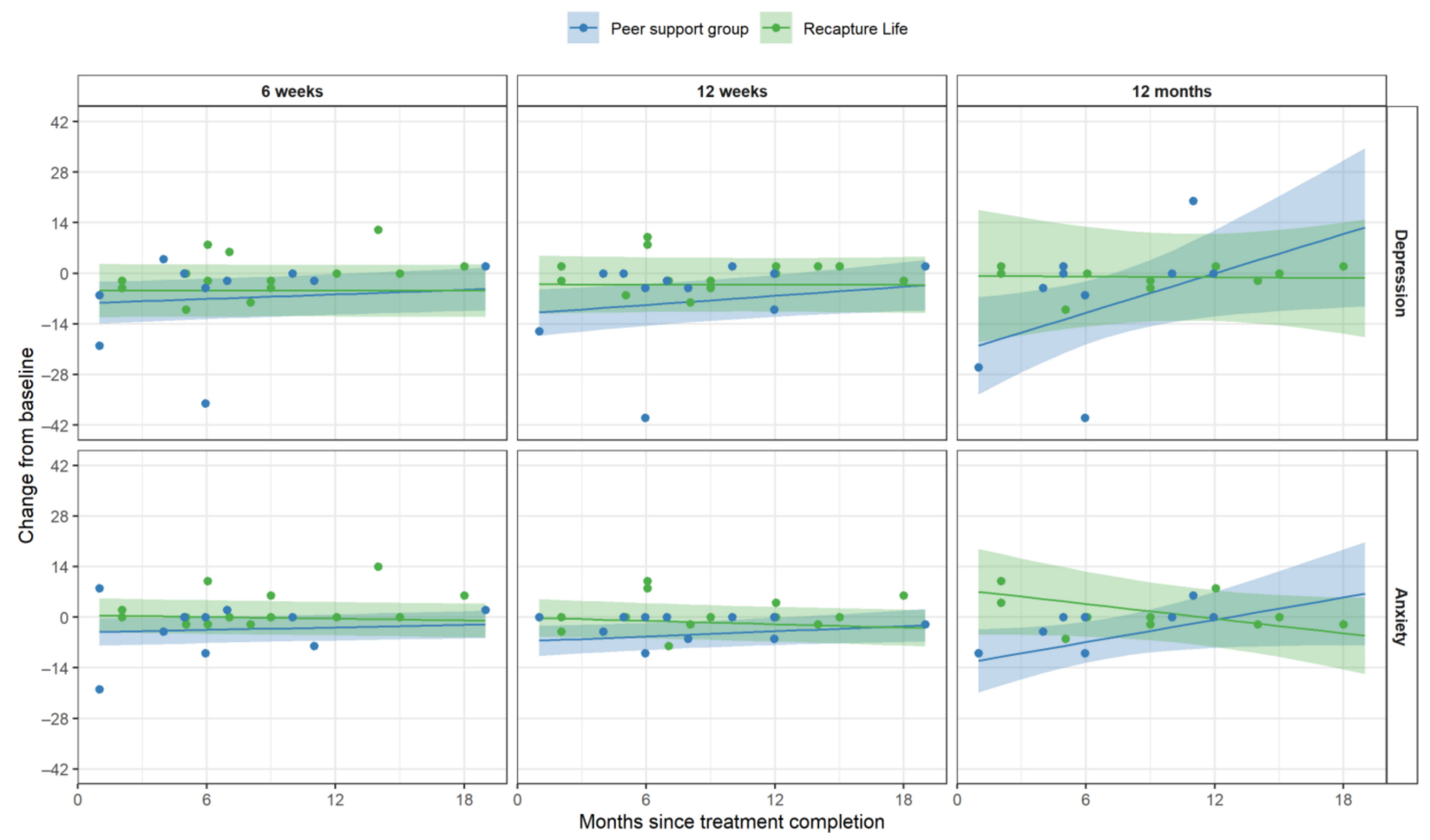

Figure 4. Between-group differences in change in depression and anxiety scores according to participants' time since treatment-completion, across time-points. Note. Individual scores are displayed, overlaid with thicker lines showing group-specific means and 95\% confidence intervals. Participants' length of time since completing cancer treatment is represented along the $\mathrm{X}$-axis (range: $0-18$ months post-treatment); while each column of panels depicts data measured at different study time-points (6-weeks, 12-weeks, 12-months).

3.3.2. Psychological Processes and Mechanisms: Cancer-Related Identity, Coping Skills and Family Functioning Cancer-Related Identity Changes

Centrality of events. On average, AYAs' scores indicated a high degree of illness centrality at each trial timepoint (Table 2). There was no evidence of between-group differences in the extent to which participants viewed their cancer experience as central to themselves/their lives, in either three-way or two-way analyses at any point ( $p$-values $\geq 0.35$ ).

Survivor identity scale. At baseline, most participants indicated that they leant towards the "survivor" end of the scale, with $87.2 \%$ scoring themselves higher than 5 ( mean $=7.4, \mathrm{SD}=1.9$; median $=7$; range $=3-10)$. While Recapture Life participants identified more strongly as 'cancer survivors' at each follow-up timepoint than peer-support group control participants, there was no evidence of significant group differences over time (all $p$-values $\geq 0.55$ ). 


\section{Coping Strategies}

Coping skills use (KIDCOPE). Looking at the total number of different coping strategies used, there was no evidence of differences between the three groups immediately following the intervention $(p=0.24)$. On average, participants in both interventions reported increased use of coping strategies at the 6-week post-intervention follow-up, and then subsequently decreased their use of coping strategies at the later 12-week and 12-month follow-ups (Table 4). However, when comparing Recapture Life to the peersupport group over time, results indicated that Recapture Life participants reported using more coping strategies at 12-weeks than did peer-support group participants (OR: 2.35, CI: $1.03-5.37, p=0.043$ ). This pattern persisted with a similar effect size, though was no longer significant 12-months post-intervention (OR: 2.39, CI: 0.94-6.04; $p=0.066$; Figure 4). From an average of 5.9 strategies used at baseline, this corresponded to a difference of 5.8 (RL) vs. 4.3 (PSG) strategies used at 12 weeks and 6.0 vs. 4.5 strategies at 12 months. Recapture Life participants also appeared somewhat (though not significantly) more likely than peer-support group participants to report that the coping strategies that they used were helpful at 6-weeks (OR: 2.05, CI: 0.89, 4.72, $p=0.091$ ), 12-weeks (OR: 2.25, CI: 0.99-5.13, $p=0.053$ ) and 12-months (OR: 2.37, CI: 0.97-5.81, $p=0.060$; See Supplementary Data S6).

CBT skills. Overall, Recapture Life participants reported feeling capable of using a greater number of CBT skills, relative to peer-support group control participants (OR: 4.59, 95\% CI: 1.19-17.76, $p=0.027$; Table 2). The difference between groups did not appear to change over time $(p=0.92)$. In relation to participants' self-reported actual use of CBT strategies, across each time point, Recapture Life participants reported 'actually using' a greater number of CBT strategies, relative to peer-support group controls. There was strong evidence that Recapture Life participants also used a higher number of CBT skills at the 6-week follow-up (OR: 5.58, 95\% CI: 2.00, 15.56, $p=0.001$; Table 4), with this difference lessening and becoming non-significant into the follow-up period (12-weeks: OR: 2.16, 95\% CI: $0.78,5.98, p=0.14 ; 12$-months: OR: 2.51, 95\% CI: 0.78, 5.98, $p=0.12$ ). Figure 5 depicts CBT skills confidence and use by treatment arm (Supplementary Data S7 depicts skills use according to individual CBT skill).



Figure 5. Cognitive-behavioral therapy skills confidence and use, by treatment arm. Note. Individual scores are displayed, overlaid with thicker lines showing group-specific means and $95 \%$ confidence intervals. 


\subsubsection{Family Functioning}

AYA outcomes. Across groups, AYAs' mean scores on perceived family functioning indicated functioning in the adaptive range on average at almost all trial time-points. At the 12-month follow-up, only the communication subscale for the peer-support group control remained in the maladaptive/problematic functioning range (Table 2). Neither three-way analyses at 6-weeks ( $p$-values $\geq 0.11$ ), nor two-way analyses up to 12-months ( $p$-values $\geq 0.10$ ) showed any evidence of groupwise differences in any changes to general, problem-solving, or communication-related family functioning.

Support person outcomes. Three-way analyses indicated there was some evidence that the support people allocated to the peer-support group control reported more adaptive general family functioning relative to the waitlist group at the 6-week follow-up $(p=0.045)$, however no other significant effects of group or time emerged from either threeor two-way analyses.

Support person unmet cancer needs. At baseline, the top three high unmet needs (ranked as high/very high needs) by support person participants were all related to their worries, about 'test results' $(11 / 16,68.9 \%)$, 'cancer returning' $(11 / 16,68.9 \%)$, and whether 'treatment worked' $(9 / 16,56.3 \%)$. The number of perceived cancer-needs mostly declined over time for support people (Table 4) but there were no between-group differences on this over time ( $p$-values $>0.10$ ). Supplementary Data S8 presents baseline cancer-related needs for AYAs' support people.

\subsubsection{Intervention Delivery: Fidelity, Group Cohesion, and Therapeutic Alliance}

Manual fidelity. Reflecting the acceptability of Recapture Life, psychologists reported adhering to all session components in $82 \%$ of sessions, with no evidence of differences between Recapture Life and peer-support control online groups $\left(X^{2}(1)=0.07, p=0.80\right)$. Two cases of 'manual deviations' were reported, both in peer-support group sessions, involving unintended provision of coping skills. Treatment fidelity of recorded sessions, as rated by two independent raters, was also acceptable: Psychologists adhered to the manualized intervention components (specific to either Recapture Life or peer-support group control) in $97 \%$ of sessions and the blinded assessors correctly identified the intervention arm on $15 / 16$ occasions $(94 \%)$.

Therapeutic working alliance and group cohesion. Across the intervention period, AYAs in both Recapture Life (Week 2: $\mathrm{M}=6.16$ [SD = 0.98]; Week 6: $\mathrm{M}=6.35$ [SD = 0.64]) and peer-support group arms (Week 2: $\mathrm{M}=6.19$ [SD = 0.82]; Week 6: $\mathrm{M}=6.06$ [SD = 0.64]) rated therapeutic alliance with their group facilitator positively (on the 7-point scale). Likewise, group cohesion scores were positive across the follow-up period (Recapture Life: 6-weeks: $\mathrm{M}=5.84$ [SD = 0.62]; 12-weeks: $\mathrm{M}=5.53$, [SD = 0.83]; Peer-support group control: 6-weeks: $\mathrm{M}=5.62$ [SD = 0.85]; 12-weeks: $\mathrm{M}=5.35$, [SD = 0.93]). We observed no evidence of differences between Recapture Life and peer-support interventions in either the average score or change over time for working alliance $(p$-value $=0.80)$ or group cohesion $(p$-value $=0.70)$.

Perceived benefit and burden of intervention. (i) AYA participants. Across both Recapture Life and peer-support control groups, the majority of AYAs reported high perceived benefit at each time point, with a slight decline over time across both groups $(p<0.01)$. There were no between-group differences in perceived benefit over time $(p=0.93)$. The majority of AYAs also indicated low burden at all timepoints, with no evidence that this changed over time either between $(p=0.55)$, or across groups $(p=0.78)$. Table 4 depicts outcome measures across intervention arms. (ii) Support persons. Most support person participants reported low burden from involvement with the study (Table 2). Relative to the peer-support group control, more support persons allocated to Recapture Life reported deriving high personal benefit immediately following the online intervention ( $83.3 \%$ vs. $20.0 \%$ at 6 weeks). However, due to the small numbers, no further statistical tests were performed. 
3.3.5. Health Economic Analyses: Real-World Functioning, Health Service and Medication Use, and Costs

Real-World Functioning

Absenteeism: Days off work or study. AYAs' self-reported absenteeism from paid work or school/university across the study period was highly variable (see Supplementary Data S9). There was no evidence to suggest that Recapture Life participants differed at any time-point to either peer-support group or waitlist controls in the number of days they took off from work or study across the timepoints, compared to baseline.

Days engaged with productive activities. There was a considerable degree of intraand inter-personal variability in AYAs' engagement with a range of productive activities across the study period (Supplementary Data S9). Although, again, there were no betweengroup differences in the mean number of days engaged in a range of productive activities over the past 28 days from baseline.

Health and mental health service use. The intervention groups did not differ in health service use at baseline. When AYAs' use of health services was examined, Recapture Life participants reported higher health service use $(p=0.05)$ between $6-12$ months postintervention compared to peer-support group control participants, after adjusting for reported use in the 6 months prior to baseline. There were no between-group differences on mental-health service use. Examined according to specific health-service type, the only significant finding was that Recapture Life participants reported accessing/seeing their GP significantly more often relative to the peer-support group at the 12-month follow-up $(p=0.015$; see Figure 6).



Figure 6. AYAs' health service use over the past six months by healthcare professional type. Note. Individual scores are displayed, overlaid with thicker lines showing group-specific means and 95\% confidence intervals. 
There was some evidence that AYAs allocated to Recapture Life reported more Emergency Department visits at 12-months compared to peer-support group control, adjusted for baseline (with 23\% Recapture Life participants (95\% CI: 8-50\%) compared with 0\% of peer-support group (95\% CI: 0-26\%); Likelihood Ratio Test $=5.87 ; p=0.015$; depicted in Supplementary Data S10). No other between-group differences emerged in relation to hospital admissions over time.

Medication use. Over half of all participants in the waitlist (73\%), peer-support (70\%) and Recapture Life (56\%) arms reported taking any medications at baseline. Two-way analyses comparing only the two online interventions indicated that while a higher proportion of the peer-support group controls reported taking medications at baseline relative to the Recapture Life group (72\% compared to 58\%) this pattern reversed somewhat over the intervention period (Supplementary Data S11). At baseline, psychotropic medication use was reported by 5 (28\%) Recapture Life participants, 2 (18\%) peer-support group participants, and no waitlist participants. At the 12-month post-intervention follow up, $5(42 \%)$ Recapture Life participants continued to take psychotropic medication, compared to no peer-support group control participants. Due to small numbers, no statistical tests were performed.

Cost of delivery. Our modelling indicated that the cost of delivering Recapture Life ranged between an estimated AU\$485-540 per participant. By contrast, the peer-support group control cost less to deliver, at an estimated AU\$365-415 per participant.

Cost to AYAs and estimated travel costs saved. We estimated that on average, our participants avoided AU $\$ 260$ in travel costs in terms of fuel costs alone, though there was a large range $(\mathrm{SD}=\$ 342.26$, range $\$ 8.95-\$ 1124.09)$.

\section{Discussion}

Coined the 'lost tribe' in supportive cancer care [98], AYAs experience numerous barriers to accessing age-appropriate, specialist mental health support following cancer treatment $[1,19,99]$. The Recapture Life trial represents one of the first attempts, worldwide, to meet the psychological needs of AYA cancer survivors using innovative online technologies. Its tailored, manualized approach ensured that evidence-based content was reliably delivered with high fidelity, and modest costs. Our inclusion of an active, peer-support group control also enabled us to assess the benefits of online support provided by a peer group, as well as any additional or specific benefits of teaching evidence-based CBT skills.

Our data provided a mixed picture of the benefit of online psychological interventions, and specifically Recapture Life, at different time-points. We did not find improvements in our primary outcome (quality of life) over the intervention period. Indeed, contrary to our hypotheses, in the follow-up period, AYAs allocated to the Recapture Life intervention demonstrated increased perceptions of the negative impact of cancer. Similarly, while depression and anxiety scores remained in the normal (non-clinical) range across the intervention and study period, the data suggested that the Recapture Life group reported higher depression and anxiety symptoms at follow-up. When length of time since treatment was taken into account, AYAs closer to treatment completion appeared to garner the greatest benefit from non-directive peer-support-groups, in terms of anxiety symptom improvement, while AYAs further from treatment completion responded better to Recapture Life. Participants in Recapture Life also reported significantly greater self-efficacy and use of coping strategies relative to peer-support participants, although these coping-skill gains were not maintained by the 12-month follow-up.

It is possible that our quality of life evaluations of Recapture Life were susceptible to the documented psychometric phenomenon of 'response shift' [100]. Response shift involves individuals' self-reported perceptions of their quality of life declining in response to a psychosocial intervention, which has heightened their level of insight and understanding around their distress and quality of life, as they integrate new understandings of how they are coping across domains. Our findings of increased perceptions of negative impact of cancer among the Recapture Life group may be consistent with this. Likewise, it is 
possible that the higher help-seeking from general practitioners, Emergency Department presentations and psychotropic medication use in the Recapture Life group similarly reflected a heightened awareness of the ongoing impact of cancer. As we did not build in measurements indexing response-shift, we cannot preclude this having had an impact on our quality of life-related outcomes. Recent longitudinal data from the BRIGHTLIGHT place of care study in the UK may echo this pattern; their data highlighted that AYAs receiving some or all of their care in hospital units specifically tailored for teenagers and young adults unexpectedly reported poorer quality of life over time, compared to AYAs who had received no care in such age-appropriate spaces [101]. The potential for the unintended, paradoxical effects of providing AYAs with peer- and cancer-related support warrants further study.

Recapture Life participants reported higher perceived negative impact of cancer, depression, and anxiety at follow-up; as such, it is possible that the skills-based model of group psychological intervention delivered through Recapture Life is not helpful for all AYA cancer survivors. Our data suggested, however, that AYA survivors may benefit from different types of online interventions at different points throughout the survivorship trajectory. Post-hoc analyses, taking into account the length of time since treatmentcompletion, suggested that our two intervention models may have been differentially beneficial for AYAs according to their passage through survivorship. Specifically, AYAs closer to treatment completion appeared to obtain more psychological benefits from the non-directive peer-support model of supportive discussion, while AYAs further into the post-treatment survivorship period appeared to derive more benefit from the CBT-based model accessed through Recapture Life. This finding warrants further investigation.

The finding that AYAs closer to treatment completion appeared to benefit the most from the non-directive peer-support model is consistent with extensive literature documenting AYAs' unmet needs for peer-support $[11,102,103]$ and perceptions of social isolation and feeling 'different' being key sources of distress [104,105]. Unlike Recapture Life, where CBT coping strategies were taught and discussed in a structured way, the peer-support group afforded more time for open-ended, non-directive peer-to-peer conversation. It may be that AYAs further from cancer treatment completion benefited more from learning CBT-based coping skills due to the increased distance gained over time from their acute hospital experiences, which may have enabled greater reflection on their cancer experiences. It is also possible that in the intervening period since finishing treatment, AYAs further into survivorship may have had time to re-integrate themselves more into routine life posttreatment, including study, work, and social relationships. AYAs further into survivorship may also simply have had more time to recover physically and cognitively, potentially enabling greater capacity to actively engage with CBT strategies. This time and experience may influence AYAs' need and motivation for learning new, adaptive coping strategies, particularly if they find that coping strategies that served them well during the active treatment period become less adaptive over time. Our trial used random allocation, and we did not assess participants' baseline degree of motivation, expectations, or preferences for different types of interventions. Consequently, it is unclear whether treatment preferences, motivation, or readiness may have played any role in the extent to which AYAs benefited from the two models of online support.

The selective-prevention approach used in Recapture Life aimed to equip AYAs with coping strategies to bolster quality of life at a known point of risk (cancer treatment completion and early survivorship). In the years since we developed Recapture Life, large-scale reviews have suggested that, while there may be some evidence to support the efficacy of selective-prevention interventions in reducing the severity of mental health disorders in the short term, longer-term data is more mixed, as is data on the efficacy of selectivepreventative interventions in preventing the onset of mental health disorders $[9,10]$. Our data indicate that those who took part remained highly-engaged throughout the intervention, increased their coping skills confidence and use, and qualitatively reported benefits [36]. This directly addresses a gap identified by AYA survivors in post-treatment 
supportive care [106]. However, given that our sample was not clinically-distressed, it may not be representative of the diversity of AYA survivors. Consequently, what was intended as a selective-prevention intervention approach (teaching coping strategies to at-risk, distressed AYAs) may have inadvertently become a universal-prevention approach (whereby we taught coping strategies to individuals who were overall not distressed), by virtue of the individuals who chose to participate.

Related to this, it is worth considering whether the demands of the multi-session intervention, together with the time and organizational skills required to participate in the trial (with multiple questionnaires across a 12-month period) may have similarly skewed our cohort towards more high-functioning individuals. Although randomized-controlled trials are considered the methodological gold-standard, researchers have also highlighted how the rigors of the recruitment processes and study designs can inadvertently impact the extent to which study findings can be generalized to the real world, over and above the role of the eligibility criteria [107]. Future research using more diverse research designs, more closely approximating how individuals select and access support in real-world settings is needed to complement more tightly-controlled trial designs, such as the one we used.

Although as a group, AYA cancer survivors share unique mental health risks and developmental vulnerabilities, our data echoes previous reports highlighting the considerable variability in survivors' functioning and psychological needs $[1,87]$. For example, our data on AYAs' real-world functioning across the study period highlighted the extent to which AYAs were functioning differently at different timepoints as they progressed further into survivorship. The notion that survivorship is a dynamically changing period-as opposed to a uniform state of adjustment post cancer-treatment-is not new [108]. For AYAs, survivorship is likely to involve multiple, interacting trajectories that could impact young people's mental health. For example, alongside the normal developmental trajectories of socio-emotional development and age-related mental health risks, AYA cancer survivors' cancer-related psychological processing is likely to be evolving as they reflect on their cancer experiences and related identity changes [18]. Additionally, as AYAs become increasingly re-integrated into life activities, they may experience the re-emergence of non-cancer-related life stressors alongside positive changes. Amidst these intersecting survivorship demands, the right time to intervene remains unclear. Understanding what kinds of support AYAs need, and when, are crucial questions that remain unanswered.

\subsection{Limitations}

The lessons learned through this trial need to be placed in the context of several limitations. Due to recruitment challenges, our trial was ultimately under-powered to detect clinically-meaningful differences in our primary outcome measure, quality of life. The significant delays we experienced in our trial to receiving ethical approval across all sites (median of 16 weeks to approval, range: 4-39 weeks) [36,94] had a cumulative flow-on effect on the overall number of AYAs ultimately approached. While our attrition rates were lower than anticipated, our response rates fell well below expectations ( $30 \%)$. Larger studies are needed to generate more conclusive data. Yet, there is growing evidence about the recruitment challenges faced by researchers testing online mental health interventions [31,109-112], with one study recruiting only 10 AYA cancer survivors out of 213 potential eligible participants contacted (4.7\%) [113]. Reviews have highlighted that randomized psychosocial studies average lower opt-in rates in pediatric psychooncology $(45.5 \%)$ relative to studies examining health behaviors $(78.2 \%)$ or neurocognitive functioning (91\%); group-based interventions also tend to yield lower opt-in rates [114]. Recruitment to pediatric psycho-oncology studies also appears more successful when face-to-face recruitment methods are used (as opposed to the letter invitation method we used), and when recruiting closer to diagnosis [115].

Our choice of quality of life as the primary outcome measure may also have been misaligned with the CBT skills-based processes targeted within our intervention. Among psychometric measures validated for AYAs, there is a predominance of quality of life 
measures [116], which are also valued within the field of health economics and prioritized by research funding bodies. While important, quality of life is also acknowledged to be a broad outcome and challenging to improve [116-118]. For AYAs in the early phases of cancer survivorship, other life events may have been more powerful than the impact of our six-week intervention in influencing their quality of life. In terms of measurement, focusing primarily on assessing common mental disorders, together with other factors important for AYAs' resilience (such as social support) may have been better.

Participants' medical risk across this early survivorship period is a relevant consideration within this trial, which included participants who had completed cancer treatment with curative intent and achieved remission. In retrospect, this likely resulted in treating our sample as more uniform than it may have been, in terms of short- versus long-term risk of relapse. Our experiences documented here, and previously [119], in terms of the relatively high number of participants who relapsed during the trial underscores the important distinction between achieving short-term remission compared with the prospect of a long-term 'cure'. Indeed, that five (12.5\%) of our total sample have died since trial intake highlights that even after 'successful' completion of cancer treatment, many of these AYAs were contending with serious health concerns. Due to our small sample, it was not possible to examine the impact of these medical factors (which varied somewhat across trial arms) on psychological outcomes with any further granularity. Whether skills-based interventions such as Recapture Life meet the psychological needs of AYAs with varying diagnoses and prognoses in survivorship therefore remains unclear.

There are several implications of these medical risks. Firstly, it is possible that variables that we did not measure-such as fear of cancer recurrence, or post-traumatic stress symptoms-may have explained the observed increases in perceived negative impact of cancer, depression, and anxiety. Recent research has highlighted the prevalence of fear of recurrence for AYA cancer survivors and the impacts of this on long-term adjustment [120]; it is possible that any AYA participants who were experiencing either clinically-significant fear of cancer recurrence, or post-traumatic stress symptoms, may not have found Recapture Life to adequately address this. Secondly, in this context, the dosage or content of Recapture Life may have been insufficient to mitigate these cancer-related stressors for some survivors, over and above the benefits of non-directive discussion and peer support. Assessing the appropriateness of survivorship interventions for AYA cancer survivors across the spectrum of prognostic outlooks is a challenge for the field and an important area for future research [119].

Our relatively small number of support person participants constrained our ability to quantify, either the benefit of the intervention to them, or the impact of their inclusion for AYAs and the family system (through broader dissemination of coping skills through AYAs' support networks). Parents and caregivers play an important role in assisting AYAs to negotiate the disruption caused by cancer [121,122], and their inclusion in skills-based programs appears to enhance AYAs' own psychological outcomes [19]. However, with the intention of not undermining AYA participants' autonomy, we made the decision in this trial to make support person participation optional. This design resulted in greater statistical complexity, as well as a smaller support person sample which limited our ability to delineate the impact of support person involvement in Recapture Life. Finally, waitlist controls are also now acknowledged to have unintended adverse effects on participants who experience them [123]. It is unclear whether and how this may have influenced our present findings, including waitlisted AYAs' subsequent experiences of the trial or either online intervention.

\subsection{Future Directions}

Our study contributes to a growing evidence base regarding online psychological interventions for AYAs living with cancer, which has been of particular interest during the global COVID-19 pandemic [22,23]. Even prior to the COVID-19 pandemic, online psychological interventions have demonstrated acceptability, feasibility, and safety with 
increasingly rigorous data for AYAs [21]. Beyond COVID-19, the acceptability patients have with telehealth interventions may be even greater. However, a remaining gap in the literature is determining what psychological intervention models are most suitable, desirable, beneficial, and at what times along the AYA cancer trajectory. Our data here and previously [36] accords with other studies in supporting the acceptability of peer-group based online interventions for those AYAs who take part [33,36], and also echo other data highlighting that not all AYAs wish to participate in formal peer-support programs with cancer survivors [122]. However, our peer-support group control clearly conferred some benefits; this may accord with recent research highlighting the potential for peer-support, including connections with AYA cancer survivors, to promote post-traumatic growth (something we did not measure) [124]. Research is needed to understand, not only the points at which AYAs are likely to gain most benefit from different forms of intervention, the relative benefits of structured versus unstructured peer-support interventions, the ideal composition for peer-group based interventions, the appropriateness of each support model for AYAs with varying degrees of distress, and importantly, when AYAs are most likely to take up these opportunities. Other research evaluating parent- and family-based interventions in oncology has indicated that perceived need, acceptability, and intervention uptake are often unrelated, and while families may express wanting interventions at a certain points of crisis (e.g., diagnosis), this may not translate into intervention uptake when given the opportunity $[125,126]$. Our data may indicate that AYAs gain greater benefit from structured, skills-based programs further into survivorship-a proposition requiring further study. Further, in-depth qualitative as well as quantitative data may illuminate what drives AYAs' choices around different types of support-seeking, and the benefits they gain from this.

Our findings on cost indicate that although online programs may be deliverable at modest per-participant costs, they still involve considerable time and resources to deliver. It remains unclear what level of 'cost' versus 'benefit' may be acceptable, and feasible, within public health contexts, as well as in not-for-profit, community-based settings where much psychosocial support in cancer survivorship is provided. Although health economic data highlights the considerable social burden of AYA cancer in terms of the quality of life years lost [127], little data has quantified the social cost of the mental health impacts of AYA cancer. Given the many life-years that stand to be gained from curative cancer treatment, it seems reasonable to expect that preventing mental health issues among AYA survivors would be associated with reduced social costs. Additionally, as newer models of survivorship support continue to be developed and evaluated internationally, it may be useful to evaluate AYA survivors' preferences for, and the relative value they place on different models of care. Health economics methodologies such as discrete choice experiments may be particularly useful in advancing knowledge on this issue.

Beyond AYAs' preferences for support models, the question remains as to which model(s) of mental health support may be most effective and appropriate in cancer survivorship, as mental health concerns among AYA cancer survivors are prevalent $[1,2]$, and are a recognized unmet need [6]. Reconciling these issues to develop scalable evidencebased models of mental health assessment, and intervention, throughout cancer survivorship poses a considerable challenge to the field. It is clear from our study and others that challenges remain in understanding how best to engage AYAs with evidence-based support. Overcoming the many barriers to seeking and accessing care for AYAs is likely to require better partnerships across the health system, including with primary care (such as general practitioners).

More broadly, the development and implementation of psychological interventions, such as the CBT-based intervention tested here, takes the approach of targeting modifiable factors at the individual level. While important, this individually-oriented approach may overlook broader contextual and social factors that are critical for good mental health at the population level [128]. There is increasing acknowledgement that the absence of mental disorders is not necessarily the same as having good mental health [9]. To achieve the 
latter, addressing the social determinants of mental health in a truly preventative way appears critical. For AYA cancer survivors, this may include proactively addressing key factors related to their ongoing social connections, smooth re-integration with family and communities, and sustained, supported engagement with education and work during and beyond cancer treatment-factors known to be linked to AYAs' mental health $[129,130]$. Future models of mental health support for AYA cancer survivors in clinical practice will need to better integrate preventative and targeted approaches to balance the dual goals of supporting good mental health of the population as a whole, whilst still addressing mental disorders of a subset in a targeted way. Advancing the field will require us to better understand the optimal strategies to use to achieve each goal.

\section{Conclusions}

This trial demonstrated that AYAs engaged well with online, supportive interventions in the first two years following cancer treatment, though recruitment was a major challenge. We did not find a positive impact of Recapture Life on quality of life, assessed as perceived impacts of cancer in the short term, which may reflect the impact of recruitment on study power. AYAs who participated in Recapture Life reported higher perceived negative impacts of cancer, anxiety, and depression at follow-up compared to a peer-support group control. Our data suggest that AYA cancer survivors may respond differently to different models of online support according to how recently they completed treatment. Understanding how best to engage AYA cancer survivors in psychological support, and at which points in time, remains a challenge for the field.

Supplementary Materials: The following are available online at https:/ / www.mdpi.com/article/10 .3390/cancers13102460/s1, S1: Example fidelity rating scales for independent raters; S2: Methodology for calculating cost of delivering Recapture Life online program; S3: Detail on composition of group members for each online group; S4: Positive (Figure a) and Negative (Figure b) Impact of Cancer outcomes from three-way analyses comparing Recapture Life, peer-support group and waitlist controls; S5: Positive and Negative Impact of Cancer outcomes plotted against participant age, by treatment group; S6: Coping strategy use and helpfulness by treatment arm; S7: Proportion of participants who reported actually using each CBT coping strategy; S8: Reported cancer-related needs at baseline on the Cancer Needs Questionnaire for Parents and Carers of AYAs; S9: Additional output related to AYAs' absenteeism (a) and productivity (b); S10: Hospital admissions and Emergency Department presentations, by treatment arm; S11: Prevalence of medication use across the trial period in Recapture Life versus peer-support group.

Author Contributions: Conceptualization: U.M.S.-D., C.E.W., S.J.E., P.B., R.A.B., S.M.S., P.P., A.A., K.T., M.P., M.O., R.J.C.; data curation: M.W.D., U.M.S.-D., C.E.W., S.J.E., B.C.M.; formal analysis: M.W.D., U.M.S.-D., C.E.W.; funding acquisition: C.E.W., U.M.S.-D., R.J.C., P.B., R.A.B., S.M.S., P.P., A.A., M.O., K.T., M.P.; investigation: U.M.S.-D., C.E.W., R.J.C., A.A., S.J.E., B.C.M., P.P., M.P.; methodology: U.M.S.-D., C.E.W., R.A.B., P.P., P.B., S.M.S., A.A., M.P., K.T., M.O., R.D.A.L., R.J.C.; project administration: U.M.S.-D., C.E.W., S.J.E., B.C.M., M.P., K.T., L.H., F.M., C.O., A.A., R.J.C.; resources: U.M.S.-D., C.E.W.; software: M.W.D.; supervision: U.M.S.-D., C.E.W., R.J.C., P.B., S.M.S., R.A.B., A.A., P.P.; visualization: M.W.D., U.M.S.-D.; writing—original draft preparation: U.M.S.-D., C.E.W., M.W.D.; writing—review and editing: U.M.S.-D., C.E.W., S.J.E., B.C.M., M.W.D., P.B., R.A.B., S.M.S., P.P., A.A., M.P., K.T., L.H., M.O., F.M., C.O., R.D.A.L., R.J.C. All authors have read and agreed to the published version of the manuscript.

Funding: The Recapture Life study was co-funded by a Beyond Blue and Cancer Australia project grant (ID: 1022868). Ursula Sansom-Daly is supported by an Early Career Fellowship from the Cancer Institute of New South Wales (ID: 2020/ECF1163) and an Early Career Fellowship from the National Health and Medical Research Council of Australia (APP1111800). Claire Wakefield is supported by a Career Development Fellowship from the National Health and Medical Research Council of Australia (APP1143767) and an Early Career Development fellowship from the Cancer Institute of NSW (ID:11/ECF/3-43). The Behavioural Sciences Unit is proudly supported by the Kids with Cancer Foundation, by the Kids Cancer Alliance, as well as a Cancer Council New South Wales Program Grant (PG16-02) with the support of the Estate of the Late Harry McPaul. 
Institutional Review Board Statement: This study was conducted according to the guidelines of the Declaration of Helsinki. Our research protocol was reviewed and approved on 26th April, 2012 by the South Eastern Sydney Local Health District Ethics Committee (HREC Ref: HREC/12/POWH/136) for delivery by Sydney Children's Hospital Randwick (Site Specific Approval Ref: SSA/SCHN/458); the Sydney Youth Cancer Service at the Prince of Wales Hospital (Ref: SSA/12/G/035); the Peter MacCallum Cancer Centre (Ref: SSA/12/PMCC/33), the Sydney Children's Hospital Westmead and Westmead Hospital (Ref: SSA/13/SCHN/252); the Princess Alexandra Hospital (Ref: SSA/13/QPAH/414); and the Hunter and Northern NSW Youth Cancer Services (Ref: SSA/14/HNE/97). Our research protocol was also reviewed and approved on the 19th of February, 2014 for delivery at Sir Charles Gairdner Hospital by the Sir Charles Gairdner Hospital and Osborne Park Health Care Group HREC (Ref: 2013-104); reviewed and approved on the 29th of March 2013 by the Royal Adelaide Hospital Research Ethics Committee (Ref: HREC/12/RAH/161) for delivery at the Royal Adelaide Hospital (Ref: SSA/13/RAH/251); and reviewed and approved on the 2nd of October, 2014 by the Princess Margaret Hospital HREC (Ref: 2014068EP) for delivery at the Princess Margaret Hospital for Children.

Informed Consent Statement: Informed consent was obtained from all subjects involved in the study.

Data Availability Statement: The data presented in this study are available upon reasonable request from the corresponding author, as is the full study protocol and the intervention materials. The data are not publicly available due to restrictions within the ethical approval.

Acknowledgments: In addition to the named authors, the wider Recapture Life Working Party includes Belinda Barton, Robert Battisti, Belinda Matigian, Lyndal Gray, Lyndal Moore, Karen Matthews, Allan Hayward, and Marianne Phillips. We would also like to thank Stephanie Arteaga, Kate Awford, Emma Doolan, Holly Evans, Kate Hetherington, Kate Marshall, Sanaa Mathur, Eden Robertson, Janine Vetsch and Helen Wilson, for their contributions to this study. The Recapture Life study was en-dorsed by the Psycho-Oncology Cooperative Research Group (PoCoG), Australia as well as the Clinical Oncology Society of Australasia's (COSA) AYA Cancer Research Steering Committee.

Conflicts of Interest: The authors declare no conflict of interest.

\section{References}

1. Sansom-Daly, U.M.; Wakefield, C.E. Distress and adjustment among adolescents and young adults with cancer: An empirical and conceptual review. Transl. Pediatr. 2013, 2, 167-197. [PubMed]

2. McCarthy, M.C.; McNeil, R.; Drew, S.; Dunt, D.; Kosola, S.; Orme, L.; Sawyer, S.M. Psychological distress and posttraumatic stress symptoms in adolescents and young adults with cancer and their parents. J. Adolesc. Young Adult Oncol. 2016, 5, 322-329. [CrossRef] [PubMed]

3. Millar, B.; Patterson, P.; Desille, N. Emerging adulthood and cancer: How unmet needs vary with time-since-treatment. Palliat. Support. Care 2010, 8, 151-158. [CrossRef] [PubMed]

4. Kessler, R.C.; Berglund, P.; Demler, O.; Jin, R.; Merikangas, K.R.; Walters, E.E. Lifetime prevalence and age-of-onset distri-butions of DSM-IV disorders in the national comorbidity survey replication. Arch. Gen. Psychiatry 2005, 62, 593-602. [CrossRef]

5. Kessler, R.C.; Chiu, W.T.; Demler, O.; Walters, E.E. Prevalence, severity, and comorbidity of 12-month DSM-IV disorders in the national comorbidity survey replication. Arch. Gen. Psychiatry 2005, 62, 617-627. [CrossRef]

6. Sawyer, S.M.; McNeil, R.; McCarthy, M.; Orme, L.; Thompson, K.; Drew, S.; Dunt, D. Unmet need for healthcare services in adolescents and young adults with cancer and their parent carers. Support. Care Cancer 2017, 25, 2229-2239. [CrossRef]

7. Zebrack, B. Information and service needs for young adult cancer survivors. Support. Care Cancer 2008, 17, 349-357. [CrossRef]

8. Medlow, S.; Patterson, P. Determining research priorities for adolescent and young adult cancer in Australia. Eur. J. Cancer Care 2015, 24, 590-599. [CrossRef]

9. Fusar-Poli, P.; Correll, C.U.; Arango, C.; Berk, M.; Patel, V.; Ioannidis, J.P.A. Preventive psychiatry: A blueprint for improving the mental health of young people. World Psychiatry 2021, 20, 764. [CrossRef]

10. Stockings, E.A.; Degenhardt, L.; Dobbins, T.; Lee, Y.Y.; Erskine, H.E.; Whiteford, H.A.; Patton, G. Preventing depression and anxiety in young people: A review of the joint efficacy of universal, selective and indicated prevention. Psychol. Med. 2016, 46, 11-26. [CrossRef]

11. Zebrack, B.; Isaacson, S. Psychosocial care of adolescent and young adult patients with cancer and survivors. J. Clin. Oncol. 2012, 30, 1221-1226. [CrossRef]

12. Zebrack, B.; Mathews-Bradshaw, B.; Siegel, S. Livestrong Young Adult Alliance. Quality cancer care for adolescents and young adults: A position statement. J. Clin. Oncol. 2010, 28, 4862-4867. [CrossRef]

13. Osborn, M.; Little, C.; Bowering, S.; Orme, L. Youth cancer services in Australia: Development and implementation. international perspectives on AYAO, Part 3. J. Adolesc. Young Adult Oncol. 2013, 2, 118-124. [CrossRef] 
14. Whiteson, M. The Teenage Cancer Trust-Advocating a model for teenage cancer services. Eur. J. Cancer 2003, 39, $2688-2693$. [CrossRef]

15. Osborn, M.; Johnson, R.; Thompson, K.; Anazodo, A.; Albritton, K.; Ferrari, A.; Stark, D. Models of care for adolescent and young adult cancer programs. Pediatr. Blood Cancer 2019, 66, e27991. [CrossRef]

16. Wakefield, C.; McLoone, J.; Butow, P.; Lenthen, K.; Cohn, R. Support after the completion of cancer treatment: Perspectives of Australian adolescents and their families. Eur. J. Cancer Care 2013, 22, 530-539. [CrossRef]

17. Baird, H.; Patterson, P.; Medlow, S.; Allison, K.R. Understanding and improving survivorship care for adolescents and young adults with cancer. J. Adolesc. Young Adult Oncol. 2019, 8, 581-586. [CrossRef]

18. Sansom-Daly, U.M.; Wakefield, C.E.; Robertson, E.G.; McGill, B.C.; Wilson, H.L.; Bryant, R.A. Adolescent and young adult cancer survivors' memory and future thinking processes place them at risk for poor mental health. Psycho-Oncology 2018, 27, 2709-2716. [CrossRef]

19. Sansom-Daly, U.M.; Peate, M.; Wakefield, C.E.; Bryant, R.A.; Cohn, R.J. A systematic review of psychological interventions for adolescents and young adults living with chronic illness. Health Psychol. 2012, 31, 380-393. [CrossRef]

20. Rabin, C.; Simpson, N.; Morrow, K.; Pinto, B. Intervention format and delivery preferences among young adult cancer sur-vivors. Int. J. Behav. Med. 2013, 20, 304-310. [CrossRef]

21. McCann, L.; McMillan, K.A.; Pugh, G. Digital interventions to support adolescents and young adults with cancer: Systematic review. J. Med. Internet Res. Cancer 2019, 5, e12071. [CrossRef] [PubMed]

22. Sansom-Daly, U.M.; Bradford, N. Grappling with the "human" problem hiding behind the technology: Telehealth during and beyond COVID-19. Psycho-Oncology 2020, 29, 1404-1408. [CrossRef] [PubMed]

23. McLoone, J.; Wakefield, C.E.; Taylor, N.; Johnston, K.; Sansom-Daly, U.M.; Cohen, J.; O’Brien, T.A.; Cohn, R.J.; Signorelli, C. The COVID-19 pandemic: Distance-delivered care for childhood cancer survivors. Pediatr. Blood Cancer 2020, 67. [CrossRef] [PubMed]

24. Christensen, H.; Hickie, I.B. Using e-health applications to deliver new mental health services. Med. J. Aust. 2010, 192, 53. [CrossRef] [PubMed]

25. Gould, M.S.; Munfakh, J.L.H.; Lubell, K.; Kleinman, M.; Parker, S. Seeking help from the internet during adolescence. J. Am. Acad. Child Adolesc. Psychiatry 2002, 41, 1182-1189. [CrossRef] [PubMed]

26. Chalmers, J.A.; Sansom-Daly, U.M.; Patterson, P.; McCowage, G.; Anazodo, A. Psychosocial assessment using telehealth in adolescents and young adults with cancer: A partially randomized patient preference pilot study. J. Med. Internet Res. Protoc. 2018, 7, e168. [CrossRef] [PubMed]

27. Kauer, S.D.; Mangan, C.; Sanci, L. Do online mental health services improve help-seeking for young people? A systematic review. J. Med. Internet Res. 2014, 16, e66. [CrossRef]

28. Australian Bureau of Statistics. Household Use of Information Technology; Australian Bureau of Statistics: Canberra, Australia, 2020.

29. Ryan, C. Computer and Internet Use in the United States: 2016; American Community Survey Reports, ACS-39; United States Census Bureau: Suitland-Silver Hill, MA, USA, 2017.

30. Office for National Statistics. Internet Access-Households and Individuals; Great Britain Statistical Bulletins; Office for National Statistics: London, UK, 2020.

31. Devine, K.A.; Viola, A.S.; Coups, E.J.; Wu, Y.P. Digital health interventions for adolescent and young adult cancer survivors. JCO Clin. Cancer Inform. 2018, 2, 1-15. [CrossRef]

32. Abrol, E.; Groszmann, M.; Pitman, A.; Hough, R.; Taylor, R.M.; Aref-Adib, G. Exploring the digital technology preferences of teenagers and young adults (TYA) with cancer and survivors: A cross-sectional service evaluation questionnaire. J. Cancer Surviv. 2017, 11, 670-682. [CrossRef]

33. McGill, B.C.; Sansom-Daly, U.M.; Wakefield, C.E.; Ellis, S.J.; Robertson, E.G.; Cohn, R.J. Therapeutic alliance and group cohesion in an online support program for adolescent and young adult cancer survivors: Lessons from "recapture life. J. Adolesc. Young Adult Oncol. 2017, 6, 568-572. [CrossRef]

34. Sansom-Daly, U.M.; Wakefield, C.E.; Mcgill, B.C.; Patterson, P. Ethical and clinical challenges delivering group-based cognitivebehavioural therapy to adolescents and young adults with cancer using videoconferencing technology. Aust. Psychol. 2015, 50, 271-278. [CrossRef]

35. Campo, R.A.; Bluth, K.; Santacroce, S.J.; Knapik, S.; Tan, J.; Gold, S.; Philips, K.; Gaylord, S.; Asher, G.N. A mindful self-compassion videoconference intervention for nationally recruited posttreatment young adult cancer survivors: Feasibility, acceptability, and psychosocial outcomes. Support. Care Cancer 2017, 25, 1759-1768. [CrossRef]

36. Sansom-Daly, U.M.; Wakefield, C.E.; Bryant, R.A.; Patterson, P.; Anazodo, A.; Butow, P.; Sawyer, S.M.; McGill, B.C.; Evans, H.E.; Cohn, R.J.; et al. Feasibility, acceptability, and safety of the Recapture Life videoconferencing intervention for adolescent and young adult cancer survivors. Psycho-Oncology 2018, 28, 284-292. [CrossRef]

37. Butler, A.C.; Chapman, J.E.; Forman, E.M.; Beck, A.T. The empirical status of cognitive-behavioral therapy: A review of meta-analyses. Clin. Psychol. Rev. 2006, 26, 17-31. [CrossRef]

38. Cartwright-Hatton, S.; Roberts, C.; Chitsabesan, P.; Fothergill, C.; Harrington, R. Systematic review of the efficacy of cognitive behaviour therapies for childhood and adolescent anxiety disorders. Br. J. Clin. Psychol. 2004, 43, 421-436. [CrossRef]

39. Durlak, J.A.; Wells, A.M. Evaluation of indicated preventive intervention (secondary prevention) mental health programs for children and adolescents. Am. J. Community Psychol. 1998, 26, 775-802. [CrossRef] 
40. Ross, X.S.; Gunn, K.M.; Olver, I.; Willems, R.A.; Lechner, L.; Mesters, I.; Bolman, C.A. Online psychosocial interventions for posttreatment cancer survivors: An international evidence review and update. Curr. Opin. Support. Palliat. Care 2020, 14, 40-50. [CrossRef]

41. Le, L.K.-D.; Sanci, L.; Chatterton, M.L.; Kauer, S.; Buhagiar, K.; Mihalopoulos, C.; Buntrock, C.; Kählke, F. the cost-effectiveness of an internet intervention to facilitate mental health help-seeking by young adults: Randomized controlled trial. J. Med. Internet Res. 2019, 21, e13065. [CrossRef]

42. Hollis, C.; Falconer, C.J.; Martin, J.L.; Whittington, C.; Stockton, S.; Glazebrook, C.; Davies, E.B. Annual Research Review: Digital health interventions for children and young people with mental health problems-A systematic and meta-review. J. Child Psychol. Psychiatry 2017, 58, 474-503. [CrossRef]

43. Sansom-Daly, U.M.; Wakefield, C.E.; Bryant, R.A.; Butow, P.; Sawyer, S.; Patterson, P.; Anazodo, A.; Thompson, K.; Cohn, R.J Online group-based cognitive-behavioral therapy for adolescents and young adults after cancer treatment: A multicenter randomised controlled trial of Recapture Life-AYA. BMC Cancer 2012, 12, 339. [CrossRef]

44. Haase, J.E. The adolescent resilience model as a guide to interventions. J. Pediatr. Oncol. Nurs. 2004, 21, 289-299. [CrossRef] [PubMed]

45. Spence, S.H.; Dadds, M.R. Preventing childhood anxiety disorders. Behav. Chang. 1996, 13, 241-249. [CrossRef]

46. World Health Organization. Prevention of Mental Disorders Effective Interventions and Policy Options; WHO: Geneva, Switzerland, 2004.

47. Butow, P.N.; Kirsten, L.T.; Ussher, J.M.; Wain, G.V.; Sandoval, M.; Hobbs, K.M.; Hodgkinson, K.; Stenlake, A. What is the ideal support group? Views of Australian people with cancer and their carers. Psycho-Oncology 2007, 16, 1039-1045. [CrossRef]

48. Mohr, D.C.; Spring, B.; Freedland, K.E.; Beckner, V.; Arean, P.; Hollon, S.D.; Ockene, J.; Kaplan, R. The selection and design of control conditions for randomized controlled trials of psychological interventions. Psychother. Psychosom. 2009, 78, 275-284. [CrossRef]

49. Biggs, K.; Hind, D.; Gossage-Worrall, R.; Sprange, K.; White, D.; Wright, J.; Chatters, R.; Berry, K.; Papaioannou, D.; Bradburn, M.; et al . Challenges in the design, planning and implementation of trials evaluating group interventions. Trials 2020, 21, 116. [CrossRef]

50. Cohen, J. Statistical Power Analysis for the Behavioural Sciences, 2nd ed.; Lawrence Erlbaum: Mahwah, NJ, USA, 1988.

51. Norman, G.R.; Sloan, J.A.; Wyrwich, K.W. Interpretation of changes in health-related quality of life. Med. Care 2003, 41, 582-592. [CrossRef]

52. Stinson, J.N.; McGrath, P.J.; Hodnett, E.D.; Feldman, B.M.; Duffy, C.M.; Huber, A.M.; Tucker, L.B.; Hetherington, C.R.; Tse, S.M.; Spiegel, L.R.; et al. An internet-based self-management program with telephone support for adolescents with arthritis: A pilot randomized controlled trial. J. Rheumatol. 2010, 37, 1944-1952. [CrossRef] [PubMed]

53. Channon, S.J.; Huws-Thomas, M.V.; Rollnick, S.; Hood, K.; Cannings-John, R.L.; Rogers, C.; Gregory, J.W. A multicenter randomized controlled trial of motivational interviewing in teenagers with diabetes. Diabetes Care 2007, 30, 1390-1395. [CrossRef] [PubMed]

54. Hampel, P.; Rudolph, H.; Stachow, R.; Petermann, F. Multimodal patient education program with stress management for childhood and adolescent asthma. Patient Educ. Couns. 2003, 49, 59-66. [CrossRef]

55. Calear, A.L.; Christensen, H. Review of internet-based prevention and treatment programs for anxiety and depression in children and adolescents. Med. J. Aust. 2010, 192, S12-S14. [CrossRef]

56. Thompson, K.; Thomas, D. A Facilitated Peer Support and Education Based Survivorship Group for Adolescents and Young Adults Living with Cancer. Building Cancer Support Groups; onTrac@PeterMac: Melbourne, VIC, Australia, 2009.

57. Geldard, K.; Geldard, D. Counseling Adolescents: The Proactive Approach; Sage: London, UK, 2001.

58. Zebrack, B.J.; Donohue, J.E.; Gurney, J.G.; Chesler, M.A.; Bhatia, S.; Landier, W. Psychometric evaluation of the impact of cancer (IOC-CS) scale for young adult survivors of childhood cancer. Qual. Life Res. 2010, 19, 207-218. [CrossRef]

59. Husson, O.; Zebrack, B.J. Psychometric evaluation of an adolescent and young adult module of the impact of cancer instrument. J. Adolesc. Young Adult Oncol. 2017, 6, 159-170. [CrossRef]

60. Lovibond, S.H.; Lovibond, P.F. Manual for the Depression Anxiety Stress Scales, 2nd ed.; Psychology Foundation: Sydney, NSW, Australia, 1995.

61. Berntsen, D.; Rubin, D.C. The centrality of event scale: A measure of integrating a trauma into one's identity and its relation to post-traumatic stress disorder symptoms. Behav. Res. Ther. 2006, 44, 219-231. [CrossRef]

62. Carey, M.L.; Clinton-McHarg, T.; Sanson-Fisher, R.W.; Shakeshaft, A. Development of cancer needs questionnaire for parents and carers of adolescents and young adults with cancer. Support. Care Cancer 2011, 20, 991-1010. [CrossRef]

63. Spirito, A.; Stark, L.J.; Williams, C. Development of a brief coping checklist for use with pediatric populations. J. Pediatr. Psychol. 1988, 13, 555-574. [CrossRef]

64. Epstein, N.B.; Baldwin, L.M.; Bishop, D.S. The McMaster Family Assessment device. J. Marital. Fam. Ther. 1983, 9, 171-180. [CrossRef]

65. Horvath, A.O.; Greenberg, L.S. Development and validation of the Working Alliance Inventory. J. Couns. Psychol. 1989, 36, 223-233. [CrossRef]

66. Gaston, L.; Marmar, C.R. The California Psychotherapy Alliance Scales. In The Working Alliance: Theory, Research and Practice; Horvath, A.O., Greenberg, L.S., Eds.; John Wiley \& Sons: New York, NY, USA, 1994; pp. 85-108. 
67. Wiener, L.; Battles, H.; Zadeh, S.; Pao, M. Assessing the experience of medically ill youth participating in psychological re-search: Benefit, burden, or both? IRB Ethics Hum. Res. 2015, 37, 1-8.

68. Kazak, A.E.; Hocking, M.C.; Ittenbach, R.F.; Meadows, A.T.; Hobbie, W.; DeRosa, B.W.; Leahey, A.; Kersun, L.; Reilly, A. A revision of the intensity of treatment rating scale: Classifying the intensity of pediatric cancer treatment. Pediatr. Blood Cancer 2012, 59, 96-99. [CrossRef]

69. Zebrack, B.; University of Michigan, Ann Arbor, MI, USA. Personal Communication, 2012.

70. Zebrack, B.J.; Landier, W. The perceived impact of cancer on quality of life for post-treatment survivors of childhood cancer. Qual. Life Res. 2011, 20, 1595-1608. [CrossRef]

71. Zebrack, B. Developing a new instrument to assess the impact of cancer in young adult survivors of childhood cancer. J. Cancer Surviv. 2009, 3, 174-180. [CrossRef]

72. Tully, P.J.; Zajac, I.T.; Venning, A.J. The structure of anxiety and depression in a normative sample of younger and older Australian adolescents. J. Abnorm. Child Psychol. 2009, 37, 717-726. [CrossRef]

73. Loh, S.Y.; Tan, F.L.; Xavier, M. Depression, anxiety and stress in women with breast cancer: Effect of a 4-week self management intervention. Malays. J. Psychiatry 2009, 18, 58-66.

74. Lovibond, P.F.; Lovibond, S.H. The structure of negative emotional states: Comparison of the Depression Anxiety Stress Scales (DASS) with the Beck Depression and Anxiety Inventories. Behav. Res. Ther. 1995, 33, 335-343. [CrossRef]

75. D'Urso, A.; Mastroyannopoulou, K.; Kirby, A.; Meiser-Stedman, R. Posttraumatic stress symptoms in young people with cancer and their siblings: Results from a UK sample. J. Psychosoc. Oncol. 2018, 36, 768-783. [CrossRef]

76. Cook, J.L.; Russell, K.; Long, A.; Phipps, S. Centrality of the childhood cancer experience and its relation to post-traumatic stress and growth. Psycho-Oncology 2021, 30, 564-570. [CrossRef]

77. Barakat, L.P.; Marmer, P.L.; A Schwartz, L. Quality of life of adolescents with cancer: Family risks and resources. Health Qual. Life Outcomes 2010, 8, 63. [CrossRef]

78. Alderfer, M.A.; Navsaria, N.; Kazak, A.E. Family functioning and posttraumatic stress disorder in adolescent survivors of childhood cancer. J. Fam. Psychol. 2009, 23, 717-725. [CrossRef]

79. Jones, J.K.; Ba, S.A.K.; Bush, P.J.; Hennessy, K.A.; Marfatia, A.; Shad, A.T. Development and evaluation of an educational interactive CD-ROM for teens with cancer. Pediatr. Blood Cancer 2010, 55, 512-519. [CrossRef]

80. Primakoff, L.; Epstein, N.; Covi, L. Homework compliance: An uncontrolled variable in cognitive therapy outcome research. Behav. Ther. 1986, 17, 433-446. [CrossRef]

81. Hawley, K.M.; Garland, A.F. Working Alliance in adolescent outpatient therapy: Youth, parent and therapist reports and associations with therapy outcomes. Child Youth Care Forum 2008, 37, 59-74. [CrossRef]

82. Andrusyna, T.P.; Tang, T.Z.; de Rubeis, R.J.; Luborsky, L. The factor structure of the Working Alliance Inventory in cognitivebehavioral therapy. J. Psychother. Pract. Res. 2001, 10, 173-178. [PubMed]

83. Lin, M.; Sansom-Daly, U.M.; Wakefield, C.E.; McGill, B.C.; Cohn, R.J. Health literacy in adolescents and young adults: Perspectives from Australian cancer survivors. J. Adolesc. Young Adult Oncol. 2017, 6, 150-158. [CrossRef] [PubMed]

84. May, E.A.; McGill, B.C.; Robertson, E.G.; Anazodo, A.; Wakefield, C.E.; Sansom-Daly, U.M. Adolescent and young adult cancer survivors' experiences of the healthcare system: A qualitative study. J. Adolesc. Young Adult Oncol. 2018, 7, 88-96. [CrossRef] [PubMed]

85. Robertson, E.G.; Sansom-Daly, U.M.; Wakefield, C.E.; Ellis, S.J.; McGill, B.C.; Doolan, E.L.; Cohn, R.J. Sexual and romantic relationships: Experiences of adolescent and young adult cancer survivors. J. Adolesc. Young Adult Oncol. 2016, 5, $286-291$. [CrossRef] [PubMed]

86. Brierley, M.E.; Sansom-Daly, U.M.; Baenziger, J.; McGill, B.; Wakefield, C.E. Impact of physical appearance changes reported by adolescent and young adult cancer survivors: A qualitative analysis. Eur. J. Cancer Care 2019, 28, e13052. [CrossRef]

87. Vetsch, J.; Wakefield, C.E.; McGill, B.C.; Cohn, R.J.; Ellis, S.J.; Stefanic, N.; Sawyer, S.M.; Zebrack, B.; Sansom-Daly, U.M. Educational and vocational goal disruption in adolescent and young adult cancer survivors. Psycho-Oncology 2018, 27, 532-538. [CrossRef]

88. R Core Team. R: A Language and Environment for Statistical Computing; R Foundation for Statistical Computing: Vienna, Austria, 2019.

89. Detry, M.A.; Lewis, R.J. The intention-to-treat principle: How to assess the true effect of choosing a medical treatment. J. Am. Med. Assoc. 2014, 312, 85-86. [CrossRef]

90. Pinheiro, J.B.D.; Deb-Roy, S.; Sarkar, D. R Core Team: Linear and Nonlinear Mixed Effects Models; R Package Version 3.1-141; R Foundation for Statistical Computing: Vienna, Austria, 2019.

91. Bates, D.; Mächler, M.; Bolker, B.; Walker, S. Fitting linear mixed-effects models using lme4. J. Stat. Softw. 2015, 67, 1-48. [CrossRef]

92. Christensen, R.H.B. Ordinal-Regression Models for Ordinal Data, R package version 2019.4-25; R Foundation for Statistical Computing: Vienna, Austria, 2019.

93. Lenth, R. Emmeans: Estimated Marginal Means, aka Least-Squares Means, R package version 1.4.3.01; R Foundation for Statistical Computing: Vienna, Austria, 2019.

94. Sansom-Daly, U.M.; Evans, H.E.; Ellis, S.J.; McGill, B.C.; Hetherington, K.; Wakefield, C.E. Something's got to give: Time-cost trade-offs in site-specific research approval can negatively impact patient recruitment in multi-institutional studies. Intern. Med. J. 2017, 47, 1088-1089. [CrossRef] 
95. Commonwealth Department of Health and Aged Care. Measuring Remoteness: Accessibility/Remoteness Index of Australia (ARIA); Commonwealth Department of Health and Aged Care: Canberra, Australia, 2001.

96. Miller, I.W.; Epstein, N.B.; Bishop, D.S.; Keitner, G.I. The McMaster Family Assessment Device: Reliability and validity. J. Marital. Fam. Ther. 1985, 11, 345-356. [CrossRef]

97. Miller, I.W.; Ryan, C.E.; Keitner, G.I.; Bishop, D.S.; Epstein, N.B. The McMaster Approach to Families: Theory, assessment, treatment and research. J. Fam. Ther. 2000, 22, 168-189. [CrossRef]

98. Stevens, M.C. The 'Lost Tribe' and the need for a promised land: The challenge of cancer in teenagers and young adults. Eur. J. Cancer 2006, 42, 280-281. [CrossRef]

99. White, V.; Skaczkowski, G.; Thompson, K.; Bibby, H.; Coory, M.; Pinkerton, R.; Nicholls, W.; Orme, L.M.; Conyers, R.; Phillips, M.B.; et al. Experiences of care of adolescents and young adults with cancer in Australia. J. Adolesc. Young Adult Oncol. 2018, 7, 315-325. [CrossRef]

100. Schwartz, C.E.; Feinberg, R.G.; Jilinskaia, E.; Applegate, J.C. An evaluation of a psychosocial intervention for survivors of childhood cancer: Paradoxical effects of response shift over time. Psycho-Oncology 1999, 8, 344-354. [CrossRef]

101. Taylor, R.M.; Fern, L.A.; Barber, J.; Alvarez-Galvez, J.; Feltbower, R.; Lea, S.; Martins, A.; Morris, S.; Hooker, L.; Gibson, F.; et al. Longitudinal cohort study of the impact of specialist cancer services for teenagers and young adults on quality of life: Outcomes from the Brightlight Sudy. BMJ Open 2020, 10, e038471. [CrossRef]

102. Cassano, J.; Nagel, K.; O'Mara, L. Talking with others who "just know": Perceptions of adolescents with cancer who participate in a teen group. J. Pediatr. Oncol. Nurs. 2008, 25, 193-199. [CrossRef]

103. Lea, S.; Martins, A.; Fern, L.A.; Bassett, M.; Cable, M.; Doig, G.; Morgan, S.; Soanes, L.; Whelan, M.; Taylor, R.M. The support and information needs of adolescents and young adults with cancer when active treatment ends. BMC Cancer 2020, 20, 1-13. [CrossRef]

104. Kent, E.E.; Wilder-Smith, A.; Keegan, T.H.M.; Lynch, C.F.; Wu, X.-C.; Hamilton, A.S.; Kato, I.; Schwartz, S.M.; Harlan, L.C. Talking about cancer and meeting peer survivors: Social information needs of adolescents and young adults diagnosed with cancer. $J$. Adolesc. Young Adult Oncol. 2013, 2, 44-52. [CrossRef]

105. Iannarino, N. My Insides Feel Like Keith Richards' Face": A narrative analysis of humor and biographical disruption in young adults cancer blogs. Health Commun. 2018, 33, 1233-1242. [CrossRef]

106. Hydeman, J.A.; Uwazurike, O.C.; Adeyemi, E.I.; Beaupin, L.K. Survivorship needs of adolescent and young adult cancer survivors: A concept mapping analysis. J. Cancer Surviv. 2019, 13, 34-42. [CrossRef]

107. Goodwin, P.J.; Leszcz, M.; Quirt, G.; Koopmans, J.; Arnold, A.; Dohan, E.; Hundleby, M.; Chochinov, H.M.; Navarro, M. Lessons learned from enrollment in the BEST study-A multicenter, randomized trial of group psychosocial support in metastatic breast cancer. J. Clin. Epidemiol. 2000, 53, 47-55. [CrossRef]

108. Miller, K.; Merry, B.; Miller, J. Seasons of survivorship revisited. Cancer J. 2008, 14, 369-374. [CrossRef]

109. Seitz, D.C.M.; Knaevelsrud, C.; Duran, G.; Waadt, S.; Loos, S.; Goldbeck, L. Efficacy of an internet-based cognitive-behavioral intervention for long-term survivors of pediatric cancer: A pilot study. Support. Care Cancer 2014, 22, 2075-2083. [CrossRef]

110. Nilsson, A.; Sörman, K.; Klingvall, J.; Ovelius, E.; Lundberg, J.; Hellner, C. MyCompass in a Swedish context-Lessons learned from the transfer of a self-guided intervention targeting mental health problems. BMC Psychiatry 2019, 19, 1-11. [CrossRef]

111. Woodford, J.; Farrand, P.; Bessant, M.; Williams, C. Recruitment into a guided Internet based CBT (iCBT) intervention for depression: Lesson learnt from the failure of a prevalence recruitment strategy. Contemp. Clin. Trials 2011, 32, 641-648. [CrossRef]

112. Zhou, E.S.; Recklitis, C.J. Internet-delivered insomnia intervention improves sleep and quality of life for adolescent and young adult cancer survivors. Pediatr. Blood Cancer 2020, 67, e28506. [CrossRef]

113. Hagström, J.; Ander, M.; Cernvall, M.; Ljótsson, B.; Wiman, H.W.; Von Essen, L.; Woodford, J. Heeding the psychological concerns of young cancer survivors: A single-arm feasibility trial of CBT and a cognitive behavioral conceptualization of distress. Peer 2020, 8, e8714. [CrossRef]

114. Brier, M.J.; Schwartz, L.A.; Kazak, A.E. Psychosocial, health-promotion, and neurocognitive interventions for survivors of childhood cancer: A systematic review. Health Psychol. 2015, 34, 130-148. [CrossRef]

115. Wakefield, C.E.; Fardell, J.E.; Doolan, E.L.; Aaronson, N.K.; Jacobsen, P.B.; Cohn, R.J.; King, M. Participation in psychosocial oncology and quality-of-life research: A systematic review. Lancet Oncol. 2017, 18, e153-e165. [CrossRef]

116. Patterson, P.; Wakefield, C.E.; McDonald, F.E.J;; Wilson, H.L.; Davis, E.; Sansom-Daly, U.M. Assessment of psychosocial outcomes in adolescents and young adults with cancer: A systematic review of available instruments. Clin. Oncol. Adolesc. Young Adults 2013, 3, 13-27. [CrossRef]

117. Carr, A.J. Measuring quality of life: Are quality of life measures patient centred? BMJ 2001, 322, 1357-1360. [CrossRef] [PubMed]

118. Higginson, I.J. Measuring quality of life: Using quality of life measures in the clinical setting. BMJ 2001, 322, 1297-1300. [CrossRef]

119. Sansom-Daly, U.M.; McGill, B.C.; Anazodo, A.C.; Plaster, M.; Maguire, F.; O’Dwyer, C.; Ellis, S.J.; Robertson, E.G.; Cohn, R.J.; Wakefield, C.E. The reality of relapse: Impact of cancer relapse on survivorship interventions and patient-reported outcomes data. Pediatr. Blood Cancer 2016, 63, 1492-1493. [CrossRef]

120. Shay, L.A.; Carpentier, M.Y.; Vernon, S.W. Prevalence and correlates of fear of recurrence among adolescent and young adult versus older adult post-treatment cancer survivors. Support. Care Cancer 2016, 24, 4689-4696. [CrossRef]

121. Corey, A.L.; Haase, J.E.; Azzouz, F.; Monahan, P.O. Social support and symptom distress in adolescents/young adults with cancer. J. Pediatr. Oncol. Nurs. 2008, 25, 275-284. [CrossRef] 
122. McNeil, R.; Egsdal, M.; Drew, S.; McCarthy, M.C.; Sawyer, S.M. The changing nature of social support for adolescents and young adults with cancer. Eur. J. Oncol. Nurs. 2019, 43, 101667. [CrossRef]

123. Furukawa, T.A.; Noma, H.; Caldwell, D.M.; Honyashiki, M.; Shinohara, K.; Imai, H.; Chen, P.; Hunot, V.; Churchill, R. Waiting list may be a nocebo condition in psychotherapy trials: A contribution from network meta-analysis. Acta Psychiatr. Scand. 2014, 130, 181-192. [CrossRef]

124. Matsui, M.; Taku, K.; Tsutsumi, R.; Ueno, M.; Seto, M.; Makimoto, A.; Yuza, Y. The role of peer support in psychosocial outcomes among adolescent and young adult (AYA) cancer survivors. J. Clin. Oncol. 2020, 38, e22528. [CrossRef]

125. Stehl, M.L.; Kazak, A.E.; Alderfer, M.A.; Rodriguez, A.; Hwang, W.-T.; Pai, A.L.H.; Boeving, A.; Reilly, A. Conducting a randomized clinical trial of an psychological intervention for parents/caregivers of children with cancer shortly after diagnosis. $J$. Pediatr. Psychol. 2008, 34, 803-816. [CrossRef]

126. Stafford, L.; Sinclair, M.; Newman, L.; Rauch, P.; Barton, M.; Gilham, L.; Cannell, J.; Mason, K.; Joubert, L.; Hocking, A.; et al. Why did we fail? Challenges recruiting parents with cancer into a psycho-educational support program. Psycho-Oncology 2019, 28, 2425-2428. [CrossRef]

127. CanTeen Australia. The Economic Cost of Cancer in Adolescents and Young Adults; CanTeen Australia: Sydney, NSW, Australia, 2017.

128. Patton, G.C.; Raniti, M.; Reavley, N. Rediscovering the mental health of populations. World Psychiatry 2021. [CrossRef]

129. Kwak, M.; Zebrack, B.J.; Meeske, K.A.; Embry, L.; Aguilar, C.; Block, R.; Hayes-Lattin, B.; Li, Y.; Butler, M.; Cole, S. Prevalence and predictors of post-traumatic stress symptoms in adolescent and young adult cancer survivors: A 1-year follow-up study. Psycho-Oncology 2012, 22, 1798-1806. [CrossRef]

130. Kwak, M.; Zebrack, B.J.; Meeske, K.A.; Embry, L.; Aguilar, C.; Block, R.; Hayes-Lattin, B.; Li, Y.; Butler, M.; Cole, S. Trajectories of psychological distress in adolescent and young adult patients with cancer: A 1-year longitudinal study. J. Clin. Oncol. 2013, 31, 2160-2166. [CrossRef] 